Florida International University FIU Digital Commons

$2-17-2017$

\title{
Enzyme Catalyzed and Ultrasound Assisted Transformation of Selected Pollutants
}

yi tan

ytan004@fiu.edu

DOI: $10.25148 /$ etd.FIDC001751

Follow this and additional works at: https://digitalcommons.fiu.edu/etd

Part of the Biochemistry Commons, and the Chemicals and Drugs Commons

\section{Recommended Citation}

tan, yi, "Enzyme Catalyzed and Ultrasound Assisted Transformation of Selected Pollutants" (2017). FIU Electronic Theses and Dissertations. 3220.

https://digitalcommons.fiu.edu/etd/3220

This work is brought to you for free and open access by the University Graduate School at FIU Digital Commons. It has been accepted for inclusion in FIU Electronic Theses and Dissertations by an authorized administrator of FIU Digital Commons. For more information, please contact dcc@fiu.edu. 


\title{
FLORIDA INTERNATIONAL UNIVERSITY
}

Miami, Florida

\section{ENZYME CATALYZED AND ULTRASOUND ASSISTED TRANSFORMATION OF SELECTED POLLUTANTS}

\author{
A thesis submitted in partial fulfillment of the \\ requirements for the degree of \\ MASTER OF SCIENCE \\ in \\ CHEMISTRY \\ by \\ Yi Tan
}

2017 
To: Dean Michael R. Heithaus

College of Arts, Sciences and Education

This thesis, written by Yi Tan, and entitled Enzyme Catalyzed and Ultrasound Assisted Transformation of Selected Pollutants, having been approved in respect to style and intellectual content, is referred to you for judgment.

We have read this thesis and recommend that it be approved.

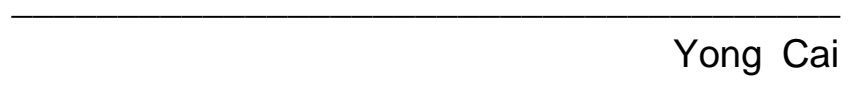

Yong Cai

Kevin O'Shea, Co-Major Professor

Xiaotang Wang, Co-Major Professor

Date of Defense: February 17, 2017

The thesis of Yi Tan is approved.

Dean Michael R. Heithaus

College of Arts, Sciences and Education

Andrés G. Gil

Vice President for Research and Economic Development and Dean of the University Graduate School

Florida International University, 2017 
(C) Copyright 2017 by Yi Tan

All rights reserved. 


\section{DEDICATION}

I would like to dedicate this dissertation to my family. Without their support and encouragement, this work would not have been completed. 


\section{ACKNOWLEDGMENTS}

The completion of this thesis would not have been possible without many people who have helped me during my study at Florida International University.

First of all, I would like to express my sincerest gratitude to my advisors, Dr. Xiaotang Wang and Dr. Kevin O'Shea, for their invaluable assistance and continuous encouragement. I would extend my appreciation to my committee, Dr. Yong Cai, for his advice and constant support.

I gratefully acknowledge all the faculty and staff members in the Department of Chemistry and Biochemistry, stock room, LC-MS facility and NMR facility. Special thanks to Dr. Watson Lees, for his support and help as the program director, to Magali Autie, for her help and coordination, to Dr. Luis Arroyo-Mora from Dr. Anthony DeCaprio's lab, for teaching me LC-Q-TOF mass spectrometry.

Many thanks to my labmates for their support and friendship. Special thanks to Cen Zhao, Qinghao He and Danni Cui for their help in my study, work and life. Finally, I wish to express my appreciation to those who have helped me in any respect during my study at FIU. It has been an unforgettable experience in my whole life to work in such a warm and kind place. 


\section{ABSTRACT OF THE THESIS \\ ENZYME CATALYZED AND ULTRASOUND ASSISTED \\ TRANSFORMATION OF SELECTED POLLUTANTS}

by

Yi Tan

Florida International University, 2017

Miami, Florida

Professor Xiaotang Wang, Co-major Professor

Professor Kevin O'Shea, Co-major Professor

The widespread use of synthetic drugs and as feed additives has resulted in the release of large amounts of biologically active chemicals into the environment. Exposure to environmentally relevant concentrations of chemicals can have severe effects on human health. Therefore, effective degradation of these synthetic, biologically active compounds is of paramount importance.

Diphenhydramine (DPH) has been selected as a target compound for ultrasound remediation. The results demonstrated that ultrasound-induced degradation has potential applications in managing aqueous media contaminated with $\mathrm{DPH}$.

Atorvastatin and roxarsone have been selected as representative substrates for chloroperoxidase (CPO) catalyzed transformation of pollutants. These studies demonstrate atorvastatin and roxarsone can be degraded efficiently by CPO. The 
transformation products of each compound were identified and the mechanisms of CPO catalysis postulated. This study provides a foundation for assessing the feasibility of applying CPO in the remediation of water and soil contaminated with pharmaceuticals and feed additives. 


\section{TABLE OF CONTENTS}

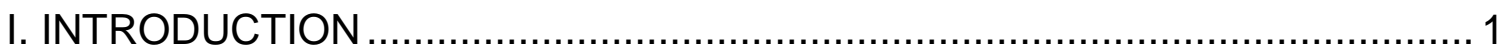

1.1 The occurrence of pharmaceutical pollutants in water ............................ 1

1.2 Treatment to remove pharmaceuticals in water .................................... 4

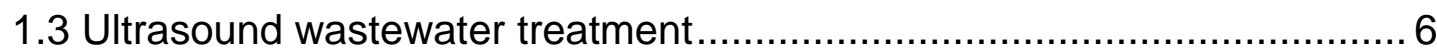

1.4 Peroxidase based enzymatic wastewater treatment .............................. 7

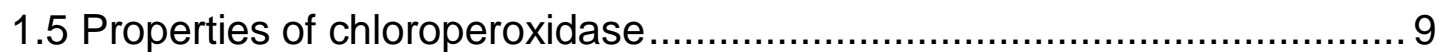

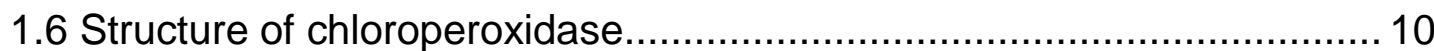

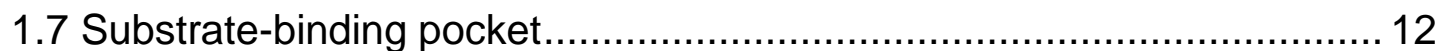

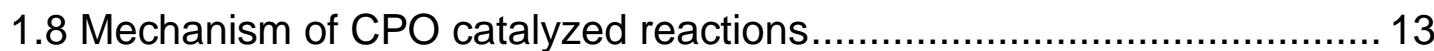

1.9 Reactions catalyze by chloroperoxidase ......................................... 15

II. ULTRASOUND ASSISTED TRANSFORMATION OF DIPHENHYDRAMINE 18

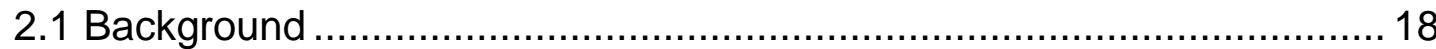

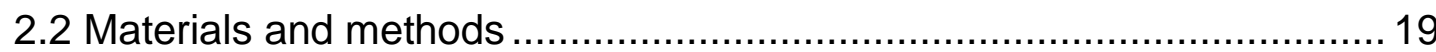

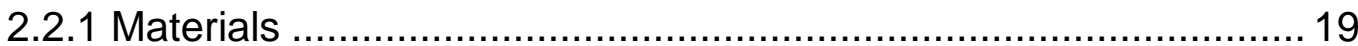

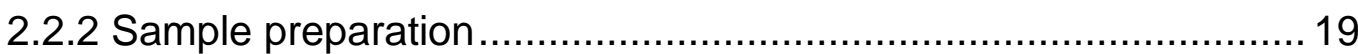

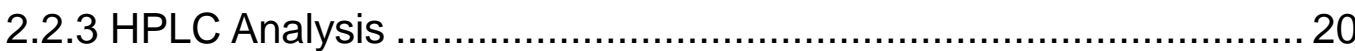

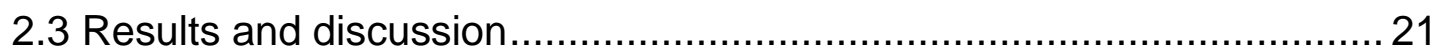

2.3.1 Transformation of DPH as a function of concentration .................. 21

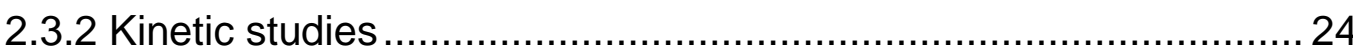

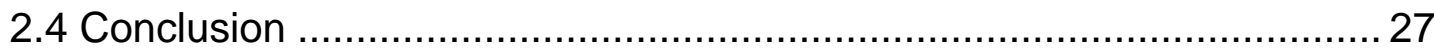

III. CPO CATALYZED TRANSFORMATION OF ATORVASTATIN ....................29

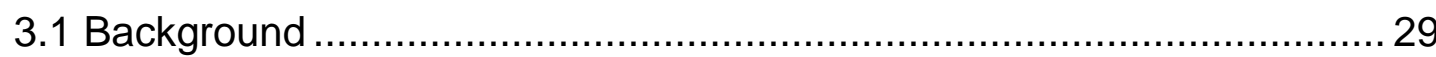

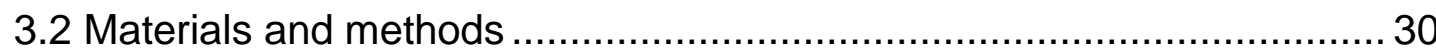

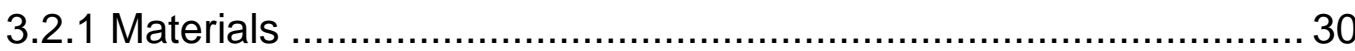

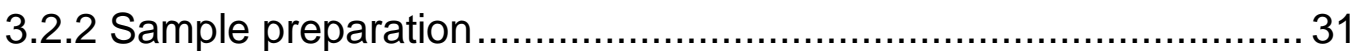

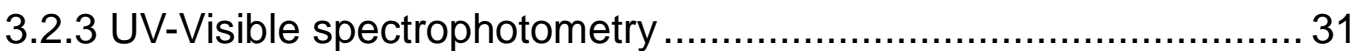

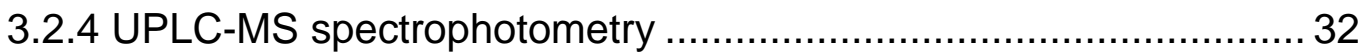

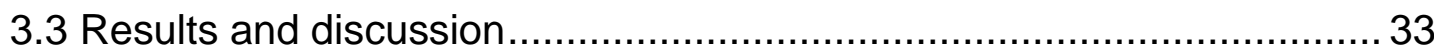

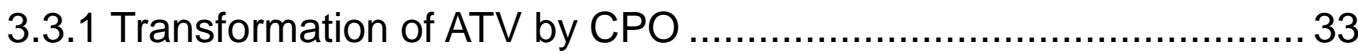

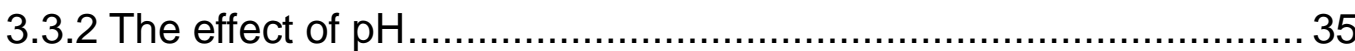

3.3.3 The effect of hydrogen peroxide concentration ............................ 36

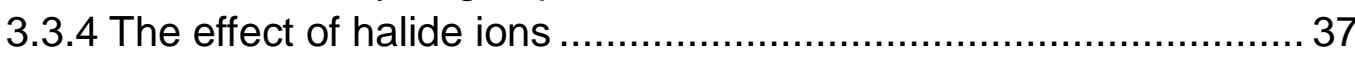

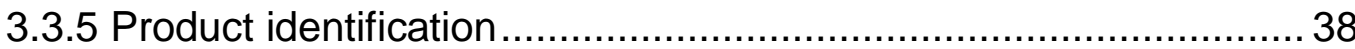

3.3.6 Mechanism of CPO-catalyzed ATV transformation ...................... 41 


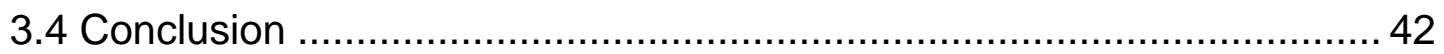

IV. CPO CATALYZED TRANSFORMATION OF ROXARSONE ....................... 44

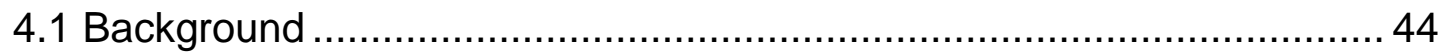

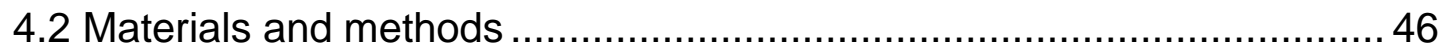

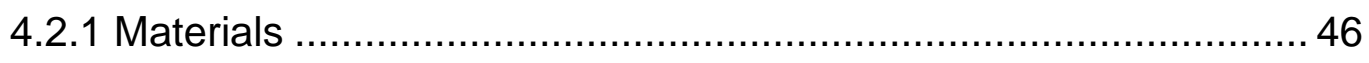

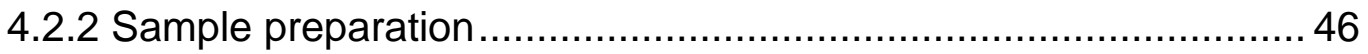

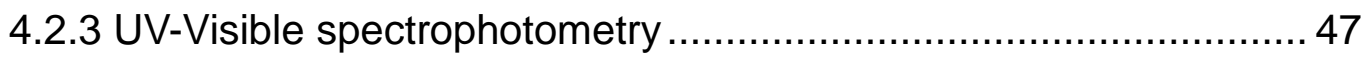

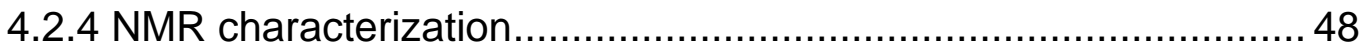

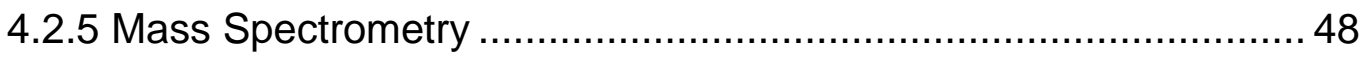

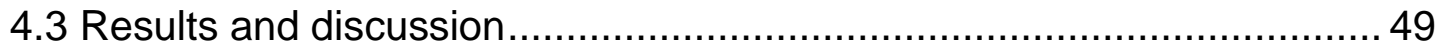

4.3.1 Transformation of ROX by CPO ……..................................... 49

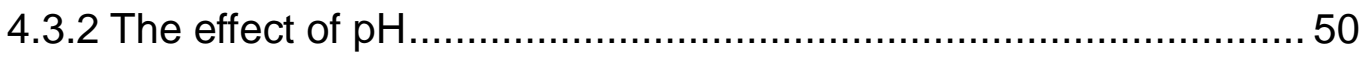

4.3.3 The effect of hydrogen peroxide concentration ........................... 51

4.3.4 Michaelis-Menten kinetics .................................................... 52

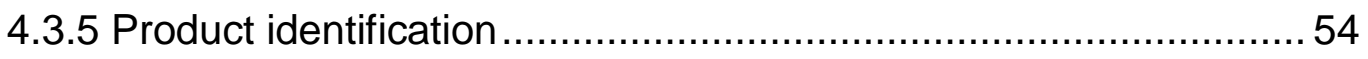

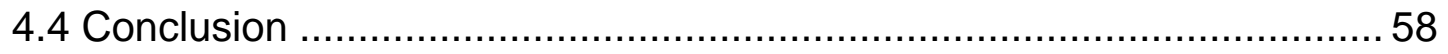

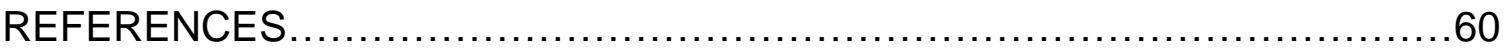




\section{LIST OF TABLES}

TABLE

PAGE

Table 1.1 Reported effects of pharmaceutical compounds on aquatic and terrestrial organisms. ............................................................... 3

Table 1.2 Conventional and advanced wastewater treatment processes and their expected range of removal efficiency for pharmaceuticals .......... 4

Table 2.1 Initial rate under different concentrations ...................................... 22

Table 2.2 Pseudo-first-order rate constants under different concentrations ...... 25

Table 3.1 Accurate-Mass LC-Q-TOF-MS data for the identification of ATV and its metabolites 40 


\section{LIST OF FIGURES}

FIGURE

PAGE

Figure 1.1 Sources, pathways, and sinks of pharmaceuticals ......................... 1

Figure 1.2 The generation of reactive oxygen species (ROS) by ultrasound ......5

Figure 1.3 Approximate frequency ranges corresponding to ultrasound, with rough guide of some applications ................................................ 6

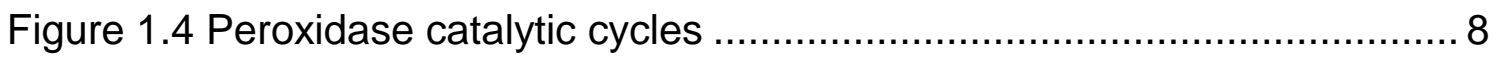

Figure 1.5 Crystal structure of CPO …................................................... 10

Figure 1.6 Stereoview of the CPO active site............................................ 11

Figure 1.7 Slice through a surface representation of CPO ............................. 12

Figure 1.8 Catalytic cycle of a heme-thiolate.............................................. 14

Figure 1.9 Chlorinated products from the enzymatic halogenation of aromatic compounds by chloroperoxidase in the presence of hydrogen peroxide and chloride ions ........................................................ 15

Figure 1.10 Enzymatic halogenation of flavones........................................ 15

Figure 1.11 Chloroperoxidase-catalyzed oxidation of 1,2-dihydronaphthalene. 16

Figure 1.12 Chloroperoxidase-catalyzed oxidation of the furan ring ................ 16

Figure 1.13 Selected nonhalogenating oxidations catalyzed by CPO …........... 17

Figure 2.1 Chemical structure of Diphenhydramine (DPH) ............................ 18

Figure 2.2 Effect of concentration on ultrasound degradation of DPH .............21

Figure 2.3 Removal of DPH during ultrasound treatment.............................. 23

Figure 2.4 First-order plot under different DPH concentrations ....................... 24

Figure 2.5 Langmuir- Hinshelwood plot of ultrasound treatment of DPH ..........26

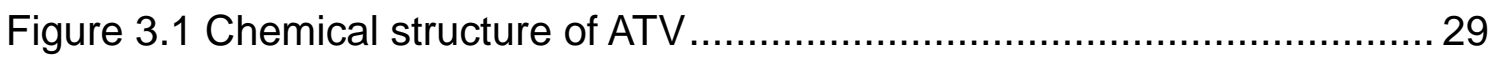


Figure 3.2 Transformation of ATV by CPO ……........................................ 33

Figure 3.3 Transformation of ATV by CPO at different times.......................... 34

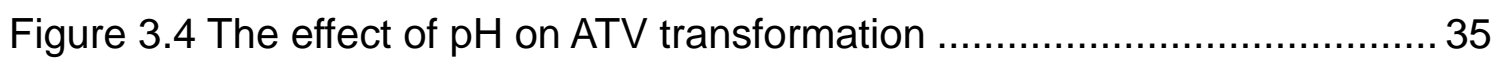

Figure 3.5 The effect of $\mathrm{H}_{2} \mathrm{O}_{2}$ concentration on ATV transformation................... 36

Figure 3.6 The effect of halide ions on ATV transformation ............................. 37

Figure 3.7 The chromatogram and MS spectra of ATV .................................. 38

Figure 3.8 The chromatogram and MS spectra of metabolites........................39

Figure 3.9 Proposed mechanism of ATV transformation ................................ 41

Figure 4.1 Chemical structure of Roxarsone (ROX) ................................... 44

Figure 4.2 Fate of ROX used as feed additives............................................ 44

Figure 4.3 Transformation of ROX by CPO ............................................. 49

Figure 4.4 The effect of $\mathrm{pH}$ on ROX transformation .......................................5 50

Figure 4.5 The effect of $\mathrm{H}_{2} \mathrm{O}_{2}$ concentration on ATV transformation.................51

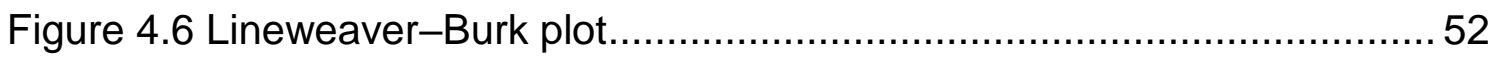

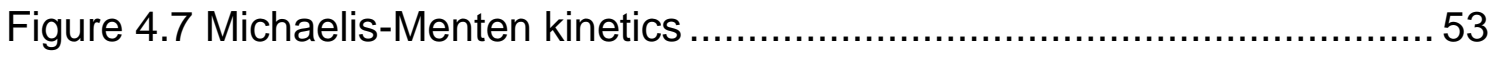

Figure 4.8 Proton NMR of ROX transformation products. ............................... 54

Figure 4.9 Mass spectra of ROX transformation products. ............................. 55

Figure 4.10 Proposed mechanism of ATV transformation ...............................5 57 


\section{CHAPTER I.}

\section{INTRODUCTION}

1.1 The occurrence of pharmaceutical pollutants in water

Pharmaceuticals are manufactured compounds used to treat disease with highly specific biological targets. The number of people on prescription drugs continues to increase dramatically. The inappropriate disposal of unused and expired medicines introduces pharmaceuticals into water systems. Most pharmaceuticals are water soluble, and a large number are regularly detected in natural and treated water systems, including drinking water supplies worldwide [1, 2]. In addition, biologically active compounds have wide spread use for agricultural and veterinary purposes and are often used as feed additives. These additives can be resistant to metabolism and are persistent in the environment. A further complication is the spread of contaminated manure when applied as fertilizer to agriculture fields.

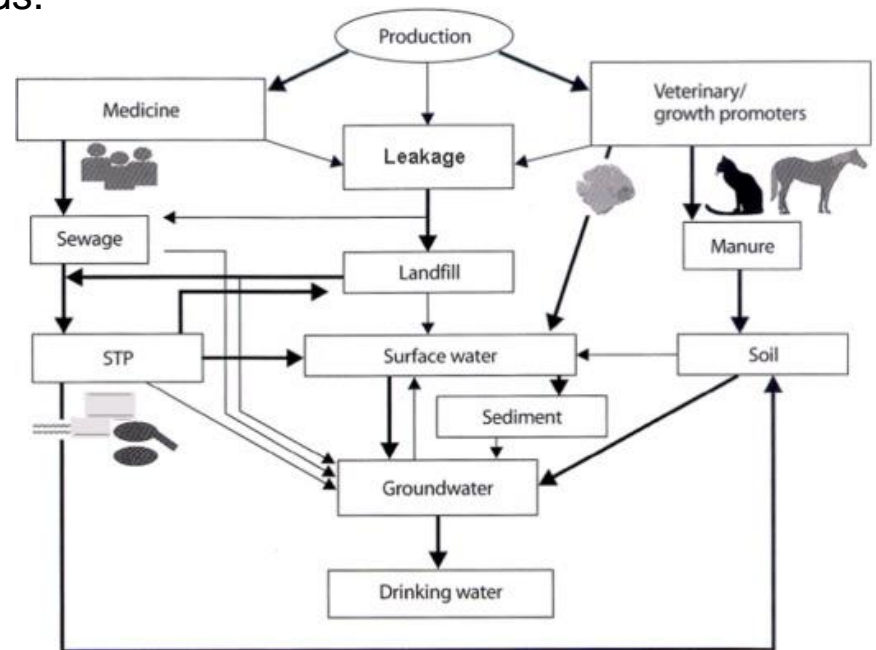

Figure 1.1 Sources, pathways, and sinks of pharmaceuticals [3]. 
Selected pharmaceuticals have been detected both in effluent water samples and aquatic animal bodies. The concentrations of 56 active pharmaceutical compounds were reported in effluent samples across the USA [4]. Hydrochlorothiazide was found in every sample, while metoprolol, atenolol, and carbamazepine were found in over $90 \%$ of the samples. Accumulation of fluoxetine and gemfibrozil in fish liver tissue has been reported: Sertraline was detected at concentrations as high as 19 and $545 \mathrm{ng} / \mathrm{g}$ in fillet and liver, respectively [5].

Pharmaceuticals can have pronounced effects on aquatic and terrestrial ecosystems. Laville and his coworkers tested the toxicity of human drugs on fish to assess the potential effects of pharmaceuticals in water [6]. Nine pharmaceuticals were tested on two fish hepatocyte models. The result showed that eight of them were cytotoxic on both cell models with the observed specific cell viability inhibition. Furthermore, a wide range of subtle impacts of pharmaceuticals has been reported (Table 1.1), including effects on aquatic plants, effects on fertility and reproduction in aquatic organisms and impacts on insect physiology and behavior [7]. To evaluate the risk to humans, there is a considerable lack of information, but the resistance to antibiotics and the disruption of endocrine systems could be included. 
Table 1.1 Reported effects of pharmaceutical compounds on aquatic and terrestrial organisms [7].

\begin{tabular}{|c|c|c|}
\hline Substrate & Medicine class & Reported effect \\
\hline Erythromycin & Antibacterial & Inhibition of growth cyanobacteria and aquatic plants \\
\hline Tetracycline & Antibacterial & $\begin{array}{l}\text { Inhibition of growth cyanobacteria and aquatic } \\
\text { plants }\end{array}$ \\
\hline Ibuprofen & Anti-inflammatory & $\begin{array}{l}\text { Stimulation of growth of cyanobacteria and } \\
\text { inhibition of growth of aquatic plants }\end{array}$ \\
\hline Avermectins & Parasiticide & $\begin{array}{l}\text { Adults insects: loss of water balance, disruption of } \\
\text { feeding and reduced fat accumulation, delayed } \\
\text { ovarian development, decreased fecundity and } \\
\text { impaired mating } \\
\text { Juvenile insects: delayed development, reduced } \\
\text { growth rates, development of physical } \\
\text { abnormalities, impairment of pupariation or } \\
\text { emergence and a loss of developmental symmetry }\end{array}$ \\
\hline
\end{tabular}

The amount of pharmaceuticals detected from wastewater treatment plant is highly dependent on the type of treatment techniques being used [8]. In general, conventional water treatment strategies do not effectively remove pharmaceuticals [9], thus development of new wastewater treatment methods is highly desired. 
1.2 Treatment to remove pharmaceuticals in water

Pharmaceuticals can be removed by wastewater treatment process as shown in Table 1.2. The removal rates expected for different wastewater treatment processes are summarized in table 1.2. As a result of the different chemical and physical characteristics of pharmaceuticals, advanced oxidation processes (AOP) can achieve higher removal compared than conventional treatment processes.

Some of the AOPs can achieve $100 \%$ transformation of pharmaceuticals for specific pollutants.

Table 1.2 Conventional and advanced wastewater treatment processes and their expected range of removal efficiency for pharmaceuticals [10].

Wastewater treatment

Removal range

Conventional wastewater treatment

Activated sludge $-193-100^{\mathrm{a}}$

Biological filtration 6-71

Primary settling 3-45

Coagulation, filtration and settling

Sand filtration $5-36$

Advanced wastewater treatment

Ozonation 1-100

Ozonation/ultrasound and sonocatalysis (\%)

Ozonation and catalytic ozonation $23-45$

UV irradiation $>9-100$

Photolysis (UV/hydrogen peroxide)

Dark and light Fenton $\mathrm{UV} / \mathrm{TiO}_{2}$ 29

Biomembrane $0-99$

Microfiltration and reverse osmosis

Reverse osmosis

Ultrasound

$52-100$

$80-100$ $>95$

23-99

91-100

62-97

24-100 
Advanced techniques to remove pharmaceuticals from wastewater include oxidation with ozone [11], filtration by nanofiltration membranes [12] and biodegradation with enzymes [13]. While these methods can be effective in the degradation of select compounds, they have several limitations, such as overall cost, low efficiency, toxic by-products and/or requirements for harsh conditions.

Advanced oxidation processes (AOPs) have been reported as a promising and effective methods in eliminating pharmaceutical pollutants [14, 15]. During advanced oxidation, hydroxyl radicals $(\mathrm{OH} \cdot)$ are generated as the major reactive oxygen species (ROS), and capable of destroying different organic compounds in water $[16,17]$. In aqueous solution, ultrasound of specific frequencies can lead to ROS production as shown in Figure1.2. The ROS can destroy a wide variety of organic compounds, and thus have great potential as an environmentally friendly water treatment technique [18].

$$
\begin{aligned}
& \mathrm{H}_{2} \mathrm{O} \stackrel{())}{\longrightarrow} \mathrm{H} \cdot+\mathrm{OH} \\
& \mathrm{O}_{2} \longrightarrow 2 \mathrm{O} \\
& \mathrm{H}+\mathrm{O}_{2} \longrightarrow \mathrm{OOH} \\
& \mathrm{O}+\mathrm{H}_{2} \mathrm{O} \longrightarrow 2 \mathrm{HO}
\end{aligned}
$$

Figure 1.2 The generation of reactive oxygen species (ROS) by ultrasound 


\subsection{Ultrasound wastewater treatment}

Ultrasonic water treatment requires sound waves at frequencies greater than 20 $\mathrm{kHz}$. Figure 1.3 shows the classification of sound determined by their different range of frequencies.

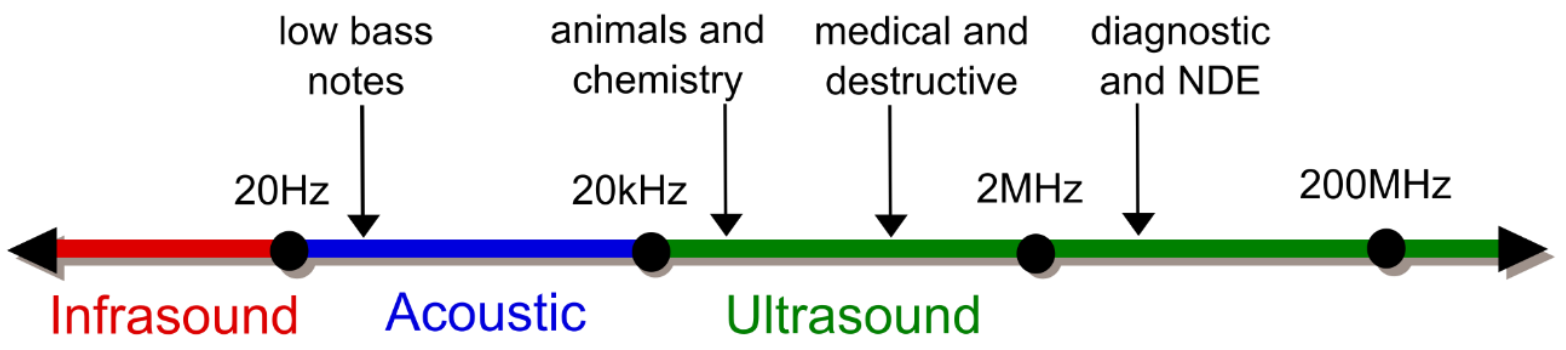

Figure 1.3 Approximate frequency ranges corresponding to ultrasound, with rough guide of some applications

Application of ultrasound to contaminated waste water leads to a series of events which degrade organic pollutants. Several mechanisms have been proposed to explain the ultrasonically induced decomposition process, primarily pyrolysis and the production of $\mathrm{ROS}(\mathrm{OH} \cdot \mathrm{H} \cdot \mathrm{and} \mathrm{OOH} \cdot)$ mediated processes. The application of ultrasound to an aqueous solution results in the formation of gas bubbles caused by pressure gradients generated by ultrasound waves passing through solution. These bubbles oscillate, in a process called cavitation, and ultimately collapse at high temperature and pressure. According to Doulah's model, the energy released by imploding cavitation bubbles in the form of shock waves is an important mechanism for the degradation of pollutants [19]. 
Ultrasound has been used to degrade a number of pollutants, such as ethyl paraben [20], ibuprofen [21], 5-methylbenzotrizole [22]. Ultrasonication is an attractive water treatment technology because it requires no additives can be effective on turbid solutions and is safe. Ultrasound can be potentially used in remediation of pharmaceutical pollutants alone or as a pretreatment for bioremediation process.

\subsection{Peroxidase based enzymatic wastewater treatment}

Biodegradation is another water treatment approach in which large molecules are converted to small ones or oxidized to less biological active compounds by using different types of microorganisms or enzymes. Microorganisms such as bacteria and fungi [23, 24], and enzymes such as horseradish peroxidase (HRP) [25] have been used in the transformation of organic pollutants in wastewater.

Peroxidases are a large family of redox-enzymes that catalyze the oxidation of a substrate by hydrogen peroxide. They function primarily as detoxification enzymes, oxidizing non-polar toxins such as pharmaceuticals to produce more easily excreted polar compounds. Peroxidases degrade substrates via the generation of free radicals, which eventually facilitate bond-cleavage reactions [26]. Peroxidase was reported to be efficient in the treatment of phenolic contaminants in wastewater treatment [27]. Peroxidases have attracted attention 
because of their ability to oxidize phenolic and nonphenolic compounds.

Typically, transformation of organic pollutants with peroxidase takes place in three steps in the presence of hydrogen peroxide. The first step of the catalytic cycle is the reaction between peroxidase and hydrogen peroxide, resulting in a Fe (IV) cation radical of the enzyme (compound I). Compound I then reacts with the substrate to form a Fe (IV) cation (compound II), which can further react with another molecule of the substrate to reset the enzyme. During the reaction, pollutant radicals are generated, which undergo degradation by participating in reactions with other species (like $\mathrm{O}_{2}$ ) in solution or reactions with themselves or other substrates in solution.

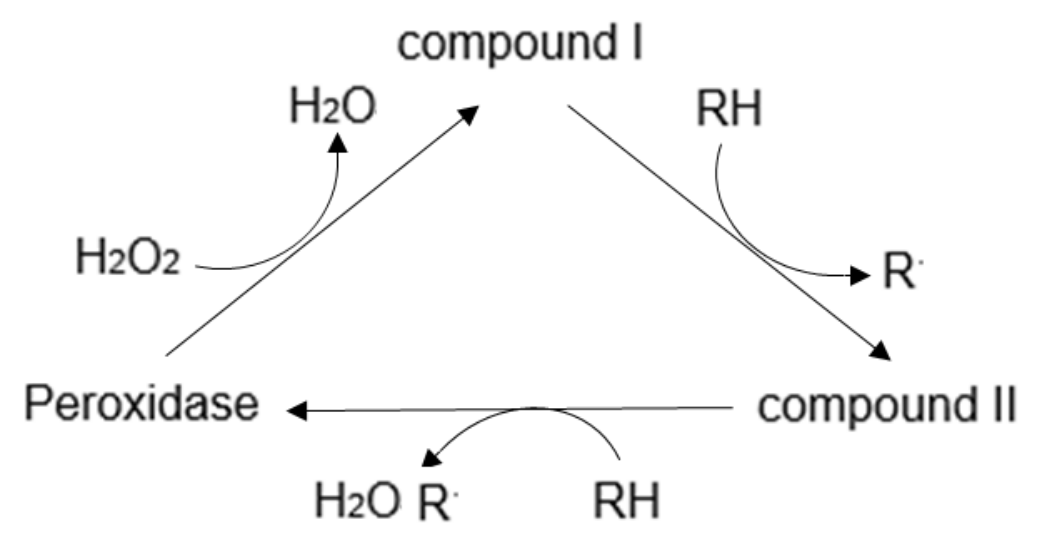

Figure 1.4 Peroxidase catalytic cycles [28]

In recent years, many studies have shown that enzyme treatment has several advantages over conventional methods, since it is environmentally friendly, cost effective and ease to handle. Furthermore, enzymatic transformation of organic 
pollutants can occur under relatively harsh conditions such as high salinity, low pH, and extreme pollutant concentrations. More importantly, the high specificity of enzymes enables the pollutants to be degraded efficiently in the presence of natural organic matter present in many drinking water sources [29]. The most commonly used peroxidases in pollutants degradation are chloroperoxidase (CPO), horseradish peroxidase (HRP), lignin peroxidase (LiP), manganese peroxidase (MnP), and lactoperoxidase (LPO). In this study, CPO will used to catalyze the transformation of selected organic pollutants.

\subsection{Properties of chloroperoxidase}

Chloroperoxidase is one of the most versatile enzymes in heme-containing family with one ferriprotoporphyrin IX prothetic group contained per enzyme molecule. Chloroperoxidase, a heme-thiolate protein, was isolated and characterized by Hager and his coworkers in 1966 [30] from the marine fungus Caldariomyces fumago (C. fumago). Chloroperoxidase is heavily glycosylated (25-30\% carbonhydrates, two high-mannose $\mathrm{N}$-glycosylation sites) with a molecular weight of approximately 42,000 Daltons [31].

The capacity of CPO to perform diverse reactions makes it one of the most versatile enzyme in heme-containing family. Chloroperoxidase catalyzes the classical peroxidation reactions as well as P-450 like reactions, which include 
halogenation, hydroxylation, peroxidation and epoxidation [32]. When catalyzing these reactions, CPO does not need cofactors but requires hydrogen peroxide $\left(\mathrm{H}_{2} \mathrm{O}_{2}\right)$ or tert-butyl hydroperoxide $(\mathrm{t}-\mathrm{BuOOH})$ as electron acceptors. Chloroperoxidase has been found in the ascomycete Emericella nidulans and the basidiomycete Agaricus bisporus [33]. Chloroperoxidase is a highly hydrophilic enzyme which makes it easy to dissolve in water. On the basis of all these characteristics, CPO has been considered a promising candidate in wastewater treatment applications.

\subsection{Structure of chloroperoxidase}

Despite functional similarities with other heme peroxidases, CPO has quite a different overall folding compared to most classical peroxidases. Chloroperoxidase folds into a tertiary structure consists of eight helical segments shown in different colors in figure 1.5 [34].

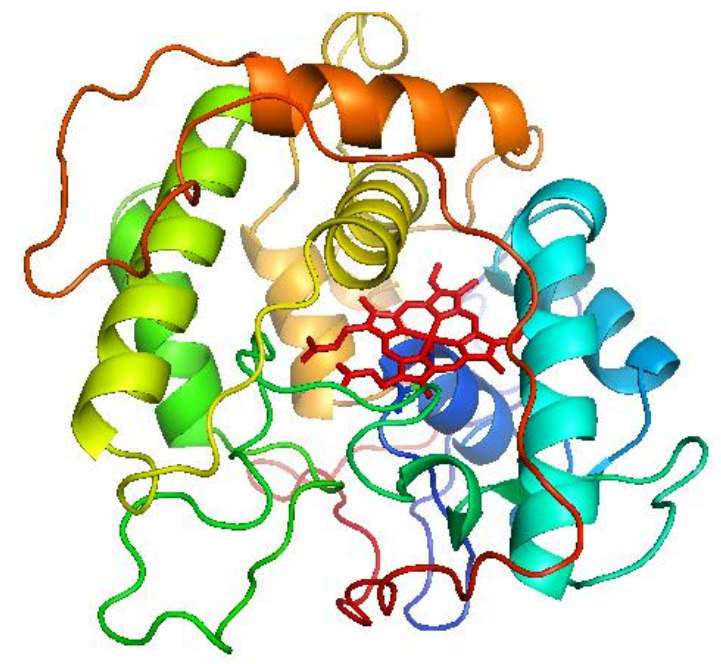

Figure 1.5 Crystal structure of CPO [34] 
The heme porphyrin ring is shown in red. Unlike other heme peroxidases that use histidine as the proximal heme iron ligand, the proximal heme ligand in CPO derives from the sulfur atom of a cysteine residue (like P450). Unlike P450 that uses mainly non-polar groups as oxygen binding site in the distal pocket, the substrate-binding site in CPO is formed primarily with polar amino acids [35, 36]. Hence, CPO is thought to have an active site hybridized from those of P450s and peroxidases.

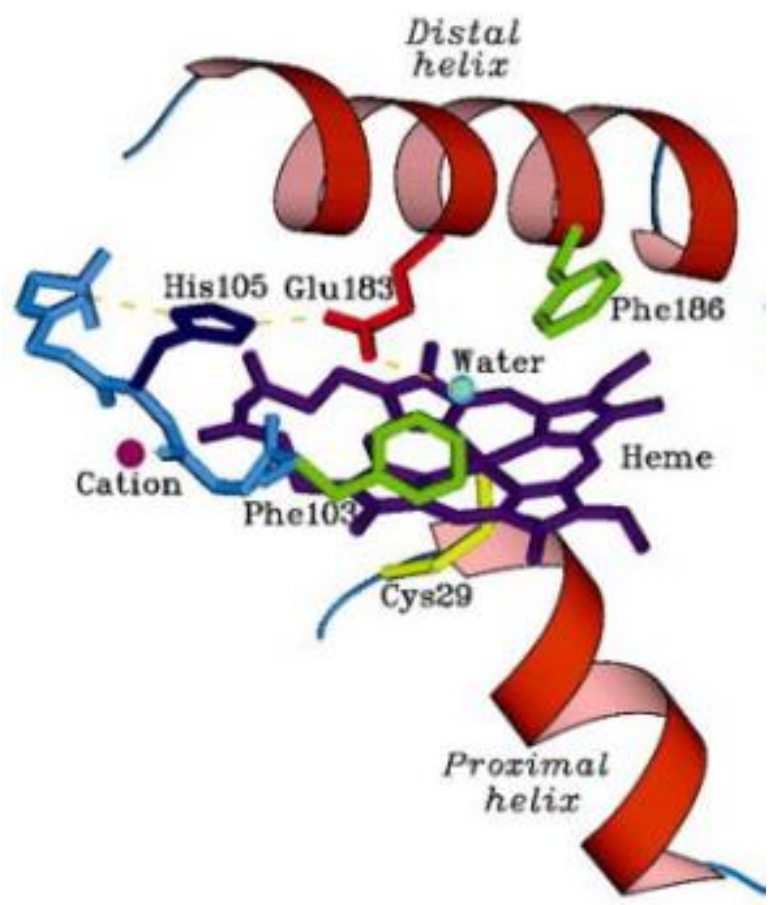

Figure 1.6 Stereoview of the CPO active site. Hydrogen bonds involving the distal side water molecule, Glu183 (the proposed acid-base catalyst) and His105 are shown as dashed lines.

The histidine is only 3.5 å from the heme propionate that binds a cation [37].

In the distal pocket of CPO, the acid-base catalytic group is glutamic acid instead of histidine find in most traditional heme peroxidases. Glutamic acid 183 can form hydrogen bond with His 105 (only $3.5 \AA$ away from the heme propionate) and 
function as a general acid-base catalyst. In Figure 1.6, the side chain of Glu 183 extends out from the distal helix to the position close to the peroxide binding site. Furthermore, the hydrogen bound between His 105 and Glu 183 facilitates the cleavage of heme bound $\mathrm{O}-\mathrm{O}$ in the formation of compound I complex. Two pheylalanine residues ( Phe 103 and Phe 186) stay close to the heme center that serves as the gate keeper in controlling substrates access to the heme active site.

\subsection{Substrate-binding pocket}

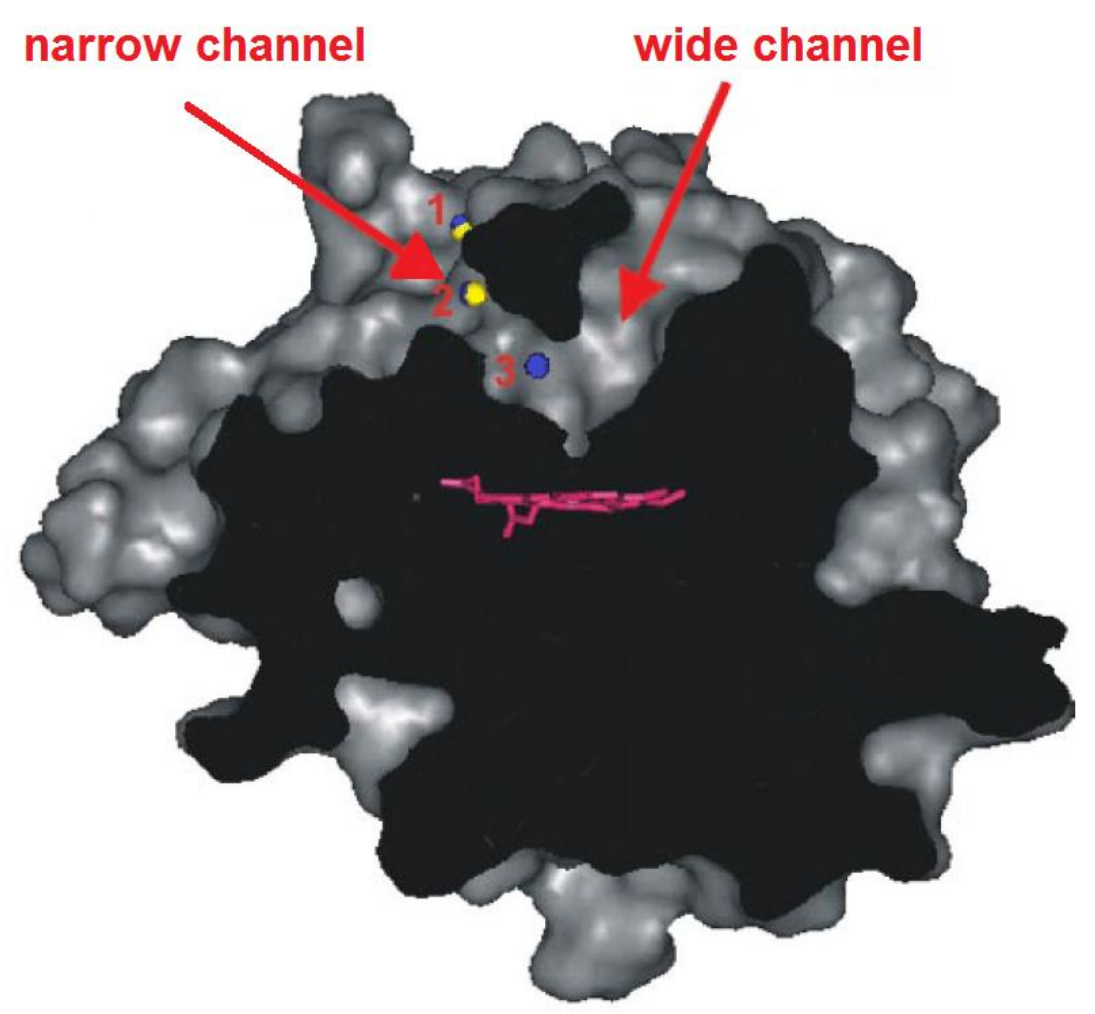

Figure 1.7 Slice through a surface representation of CPO (including sugars attached to the protein). The two channels leading to the active site are marked by arrows, and the heme is shown in magenta. The halide binding site 2 (yellow sphere, bromide; blue, iodide) is located within the narrow channel and the iodide specific binding site 3 at the end of the channel implicating a pathway for halide access from the surface (site 1) to the heme though this narrow channel. [38] 
Unlike other peroxidases whose heme edge is available for substrate access, a substrate binding pocket is required for CPO to hold the substrate in place. There are two channels for substrate to enter the heme active center of CPO from the enzyme surface, the narrow channel and the wide channel [38]. Most halide binding sites are located in the narrow channel, which indicates it is the major channel for halide ions to access the active oxoferryl center. The narrow channel is mostly hydrophobic near the heme center but more polar and further away from the center (Figure 1.7), which could hold the substrate in place for stereospecific transformations.

\subsection{Mechanism of CPO catalyzed reactions}

The unique structure of CPO allows it to have multiple functions in catalyzing a variety of reactions. Chloroperoxidase was found to follow the catalytic cycle of a heme-thiolate haloperoxidase as shown in Figure 1.8. The catalytic cycle is initiated by the heterolytic cleavage of the $\mathrm{O}-\mathrm{O}$ bond in $\mathrm{H}_{2} \mathrm{O}_{2}$ by transferring two electrons from the heme center. During the reaction, water and an oxo-ferryl cation radical intermediate (compound I) are generated. Compound I is an active intermediate and is involved in different types of chemical reactions. In one pathway, compound I reacts with the substrate $(\mathrm{RH})$ to form an oxoiron (IV) unit (compound II). Then compound II can either be reduced back to the resting state of the enzyme or undergo the classic peroxidase pathway. 


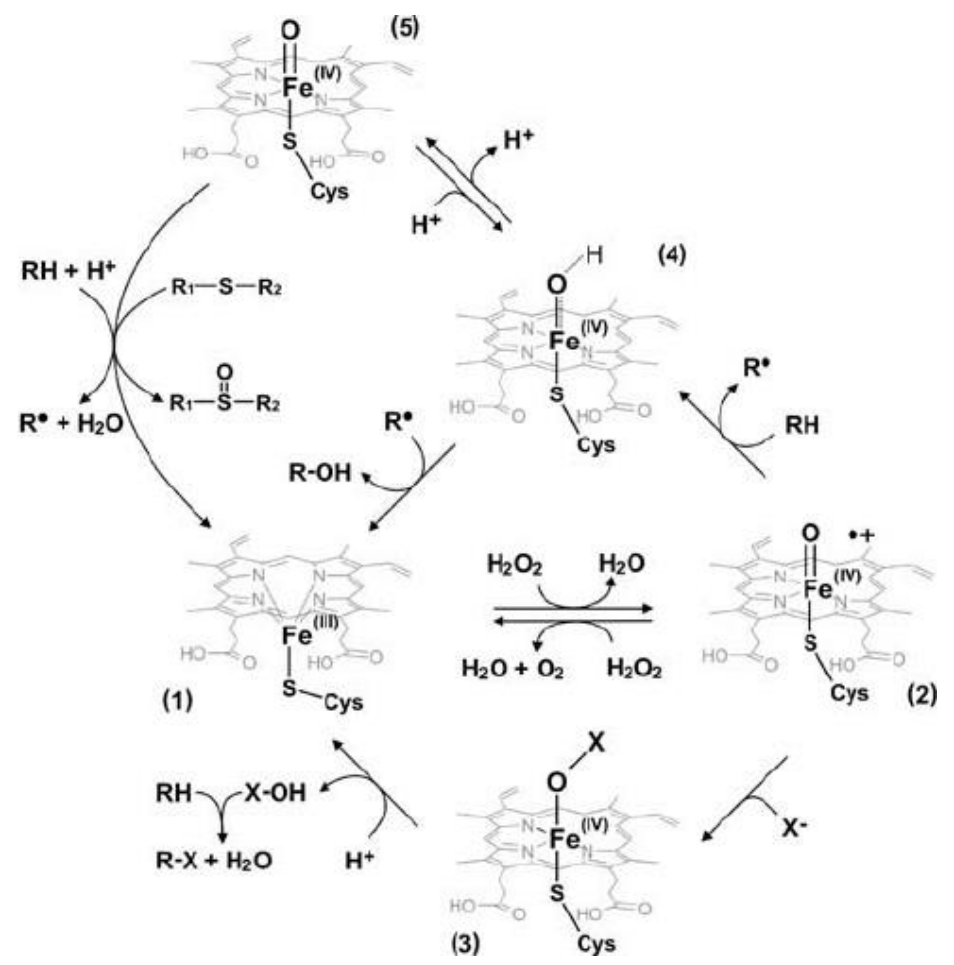

Figure 1.8 Catalytic cycle of a heme-thiolate

(1) Resting ferric enzyme, (2) compound I, (3) compound X that releases hypohalous acid (HOX), (4) protonated compound II, (5) compound II. Classic peroxidase reaction (e.g., phenol oxidation):

$(2) \Rightarrow(4) \Rightarrow(5) \Rightarrow(1)$ (without oxygen transfer to the substrate); halogenation: (3) $\Rightarrow$ (1); hydroxylation (e.g. OH-transfer to benzylic carbon, see also Fig. 3: (4) $\Rightarrow(1)$; oxygenation (e.g. sulfoxidation): (5) $\Rightarrow$ (1) (oxygen transfer to the substrate [39]

Compound I can also capture halide ion (X-) to give a hypochlorite adduct Fe-OX (compound $\mathrm{X}$ ). Compound $\mathrm{X}$ is unstable and can be protonated in acidic environment. Eventually a hypohalous acid (HOX) forms and subsequently can react with available organic substrates susceptible to electrophilic attack. Whether the HOX is released to the solution or remains associated with COP remains controversial [40,41], but recent reports that describe the reaction between chlorine and different substrates indicates that HOX diffuses into the solution instead of binding to the active site [42]. 


\subsection{Reactions catalyzed by chloroperoxidase}

Chloroperoxidase can catalyze a variety of reactions which include halogenation, hydroxylation and many types of oxidation reactions. Halogenation by CPO usually happens in solution at $\mathrm{pH}$ less than 3. Substrates susceptible to halogenation include a variety of structures, such as polycyclic aromatic hydrocarbons [43] and flavonoids [44].

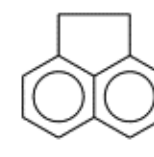

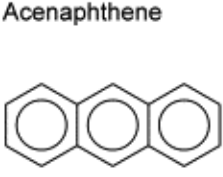

Anthracene

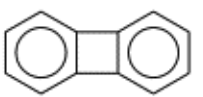

Biphenylene

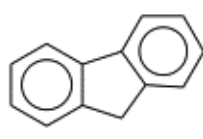

Fluorene

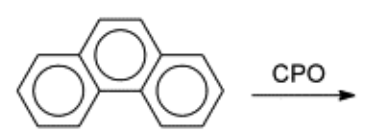

Phenanthrene

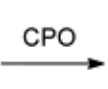

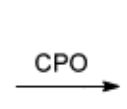
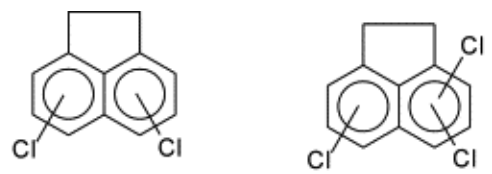<smiles>Clc1c2ccccc2c(Cl)c2ccccc12</smiles><smiles>ClC1=Cc2c(Cl)c(Cl)c3c(c2=C1)=CC=C3</smiles>

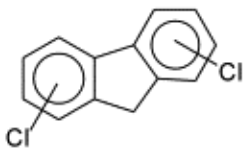

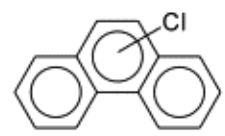

Figure 1.9 Chlorinated products from the enzymatic halogenation of aromatic compounds by chloroperoxidase in the presence of hydrogen peroxide and chloride ions. [43]

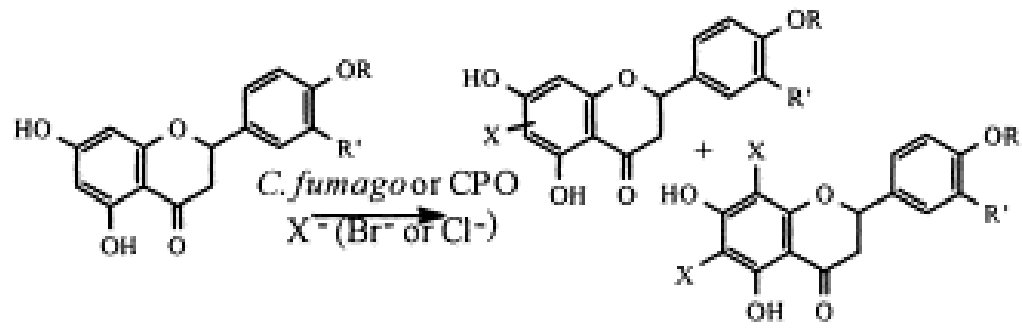

Figure 1.10 Enzymatic halogenation of flavones [44] 
Efficient hydroxylation of organic substrates has also been achieved with this peroxidase. Chloroperoxidase is able to catalyze the hydroxylation of 1,2-dihydronaphthalene with t-butyl hydroperoxide as oxidant [45], the hydroxylation of the furan ring with hydrogen peroxide as an $\mathrm{O}_{2}$ donor [46]. All of these are halide-dependent reactions and require the participation of halide ions.

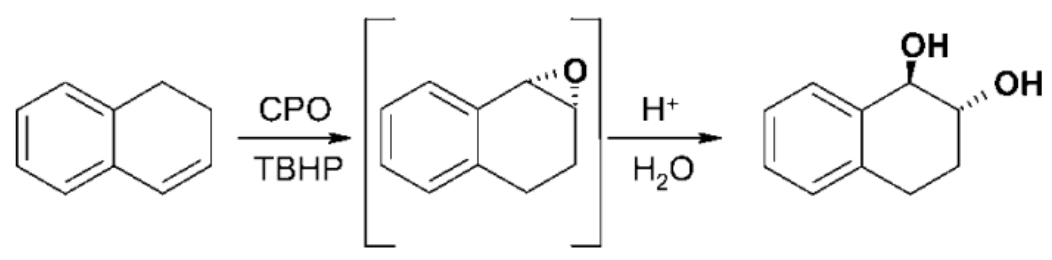

Figure 1.11 Chloroperoxidase-catalyzed oxidation of 1,2-dihydronaphthalene [45].

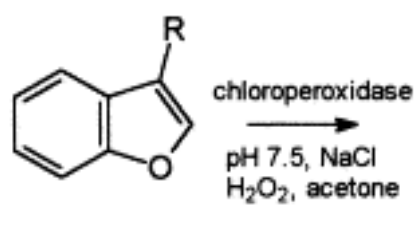<smiles>[R]C1(O)c2ccccc2OC1O</smiles><smiles>[R]C1(O)c2ccccc2OC1O</smiles>
$\mathrm{R}=\mathrm{Me}, \mathrm{Et}, \mathrm{Pr}_{1} \mathrm{CH}_{2} \mathrm{CO}_{2} \mathrm{Me}$

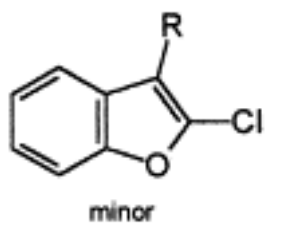

Figure 1.12 Chloroperoxidase-catalyzed oxidation of the furan ring [46].

Besides halogenation and hydroxylation, CPO is able to catalyze a number of oxidations independent of halide ions including oxidation of the amino group [47], enantioselective sulfoxidation of thioanisole [33] and N-dealkylation [48], etc. 
1

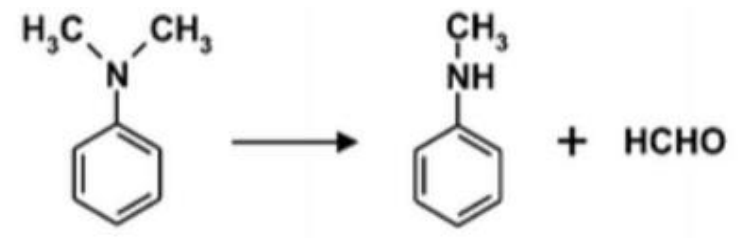

2<smiles>Nc1ccc(Cl)cc1</smiles>

3<smiles>CSc1ccccc1</smiles>

Figure 1.13 Selected nonhalogenating oxidations catalyzed by CPO. 1 demethylation of $\mathrm{N}, \mathrm{N}$-dimethylaniline; 2 oxidation of the amino group of chloroaniline into the corresponding nitroso compound; 3 enantioselective sulfoxidation of thioanisole into the corresponding $(R)$-sulfoxide [33, $47,48]$.

The goal of this study is to examine the potential effectiveness of ultrasound and CPO-based enzymatic degradation for the removal of selected pollutants in water. Detailed kinetic study and product analysis have been carried out to better understand the transformation process. The kinetic study help for modeling treatment for real applications. Based on the products identified, the mechanisms of the transformation are postulated. 


\section{CHAPTER II.}

\section{ULTRASOUND ASSISTED TRANSFORMATION OF DIPHENHYDRAMINE}

\subsection{Background}

Diphenhydramine (DPH), also known as Benadryl, is a member of the ethanolamine-based antihistamine family. It is one of the first antihistaminic agents and was discovered in 1946. The main use of diphenhydramine is to treat allergies. Diphenhydramine was the most commonly used antihistamine in 2007 [49]. Topical use of diphenhydramine to relieve itching is also common, including as sprays and lotions. Diphenhydramine has been detected in water and in shellfish bodies. The bioaccumulation factor for diphenhydramine is 118-218 in marine shellfish [50], which has the potential to be transferred to humans through marine food webs. Therefore, there is an urgent need to find an effective method to remove DPH from natural water bodies and drinking water sources.

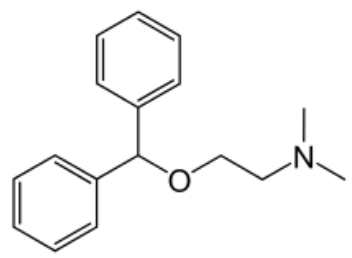

Figure 2.1 Chemical structure of Diphenhydramine (DPH)

The aim of this project is to investigate the potential application of ultrasound in the degradation of DPH. Degradation efficiency and detailed kinetics studies were conducted to assess the effectiveness of ultrasound for degradation of DPH in aqueous media. 
2.2 Materials and methods

\subsubsection{Materials}

The DPH standard was in the form of diphenhydramine hydrochloride $(10 \mathrm{~g})$ and was purchased from MP Biomedicals, LLC. The HPLC grade acetonitrile was purchased from Fisher Scientific. All reagents were used as received. All aqueous solutions were prepared with Millipore filtered water and volumetric lab equipment.

\subsubsection{Sample preparation}

An ultrasonic generator equipped with a $500 \mathrm{ml}$ reaction vessel was used to conduct the study. All solutions were prepared in a $500 \mathrm{ml}$ volumetric flask using Millipore filtered water. The mixture was then transferred to the ultrasonic vessel. The frequency, pulse, amplitude and repetition of the generator were all set in the medium value. The solution was gently purged with $\mathrm{O}_{2}$ for 15 min and rubber septum was used to seal the vessel. The reaction vessel was placed in a tank filled with ice water to maintain a temperature around $10^{\circ} \mathrm{C}$. A $10 \mathrm{ml}$ syringe was filled with oxygen and inserted into the vessel to replace the solution being collected for sampling. The syringe was rinsed with deionized water between sample collections. Samples were collected at different treatment times for HPLC analysis. 


\subsubsection{HPLC Analysis}

The concentration of DPH was monitored by a Varian ProStar HPLC, equipped with a ProStar 410 autosampler and a ProStar 335 photodiode array detector under the following conditions: a reversed phase $\mathrm{C} 18$ column $(5 \mu \mathrm{l}, 250 \times 4.6 \mathrm{~mm})$ with a constant solvent ratio of $A$ : $B$ 60:40. Solvent $A$ was $20 \mathrm{mM} \mathrm{NaH}_{2} \mathrm{PO}_{4}$ acidified to $\mathrm{pH} 2.84$ using $\mathrm{H}_{3} \mathrm{PO}_{4}$. ( $\mathrm{pH}$ might be lower to avoid trailing to get a better peak shape.) Solvent B was acetonitrile. A volume of $30 \mu$ sample was injected and a flow rate of $1 \mathrm{ml} / \mathrm{min}$ was used for elution. The detection wavelength was set at $216 \mathrm{~nm}$. 


\subsection{Results and discussion}

\subsubsection{Transformation of DPH as a function of concentration}
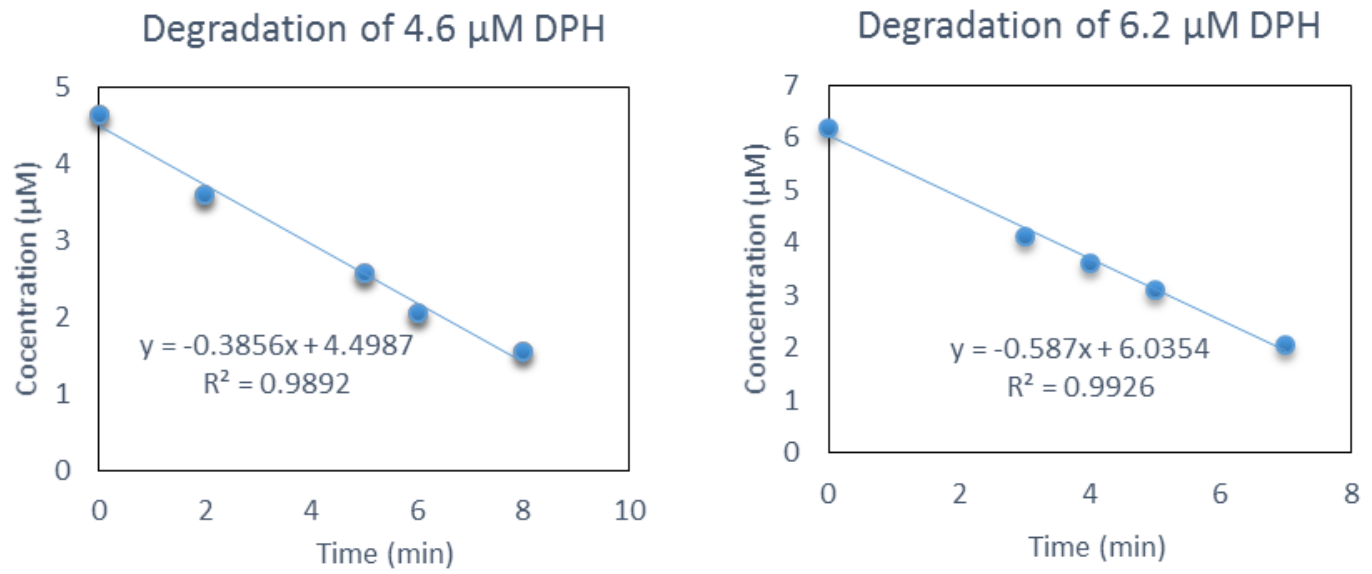

Degradation of $18.5 \mu \mathrm{M}$ DPH

Degradation of $40.1 \mu \mathrm{M}$ DPH
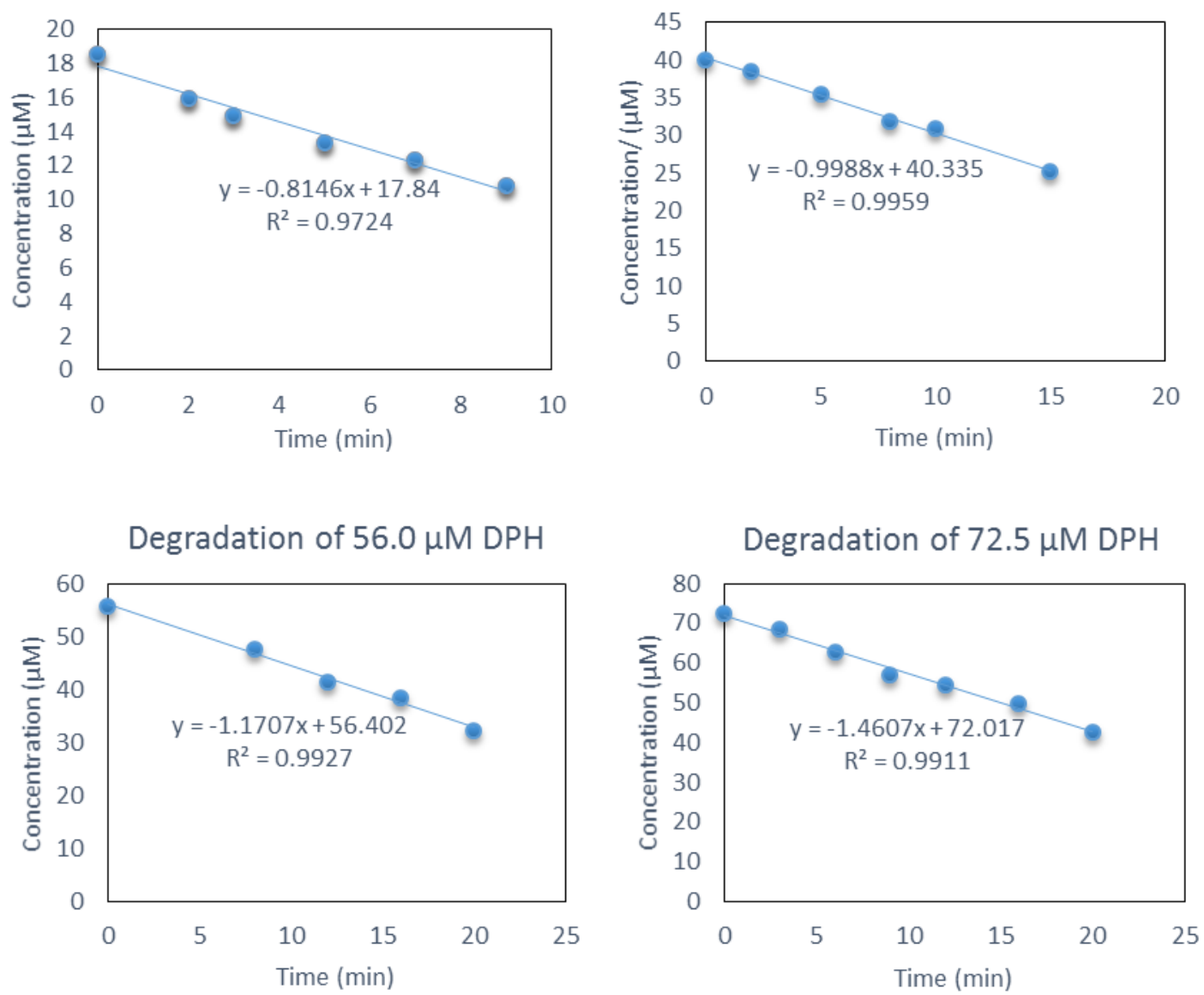

Figure 2.2 Effect of concentration on ultrasound degradation of DPH 
The ultrasonically induced degradation was monitored at different initial concentrations varying from 4.6 to $72.5 \mu \mathrm{M}$ (Figure 2.2). The concentration was plotted as a function of treatment time and the data fit to the best line with the slope representing the observed degradation rate. The results demonstrate ultrasound was effective for the degradation of DPH over different concentrations. To minimize the effect of by-products only the first $10-20 \%$ degradation was considered in measuring the initial degradation rate. The observed initial rates are $0.386 \mu \mathrm{M} \cdot \mathrm{min}^{-1}$ for $4.6 \mu \mathrm{M}, 0.587 \mu \mathrm{M} \cdot \mathrm{min}^{-1}$ for $6.2 \mu \mathrm{M}, 0.815 \mu \mathrm{M} \cdot \mathrm{min}^{-1}$ for 18.5 $\mu \mathrm{M}, 0.999 \mu \mathrm{M} \cdot \min ^{-1}$ for $40.1 \mu \mathrm{M}, 1.171 \mu \mathrm{M} \cdot \min ^{-1}$ for $56.0 \mu \mathrm{M}, 1.461 \mu \mathrm{M} \cdot \mathrm{min}^{-1}$ for $72.5 \mu \mathrm{M}$ (Table 2.1). Based on these results, the initial rate incresed as the concentration increased, which can be explanied by the existence of more DPH molecules at high concentration to be degradated by the steady state of ROS generated or decomposed by pyrolysis.

Table 2.1 Initial rate under different concentrations

\begin{tabular}{cc}
\hline \hline$C(\mu M)$ & $R\left(\mu M \cdot \mathrm{min}^{-1}\right)$ \\
\hline \hline 4.6 & 0.386 \\
6.2 & 0.587 \\
18.5 & 0.815 \\
40.1 & 0.999 \\
56.0 & 1.171 \\
72.5 & 1.461 \\
\hline \hline
\end{tabular}


The degradation of different concentrations of DPH as a function of time is illustrated in Figure 2.3. The plot of DPH removal, [DPH] / [DPH]o as a function of time shows less time in the removal of DPH at low concentration $(4.6 \mu \mathrm{M}$ and 6.2 $\mu \mathrm{M})$. As concentration increases $(56 \mu \mathrm{M}$ and $72.5 \mu \mathrm{M})$, the removal efficiency decreased.

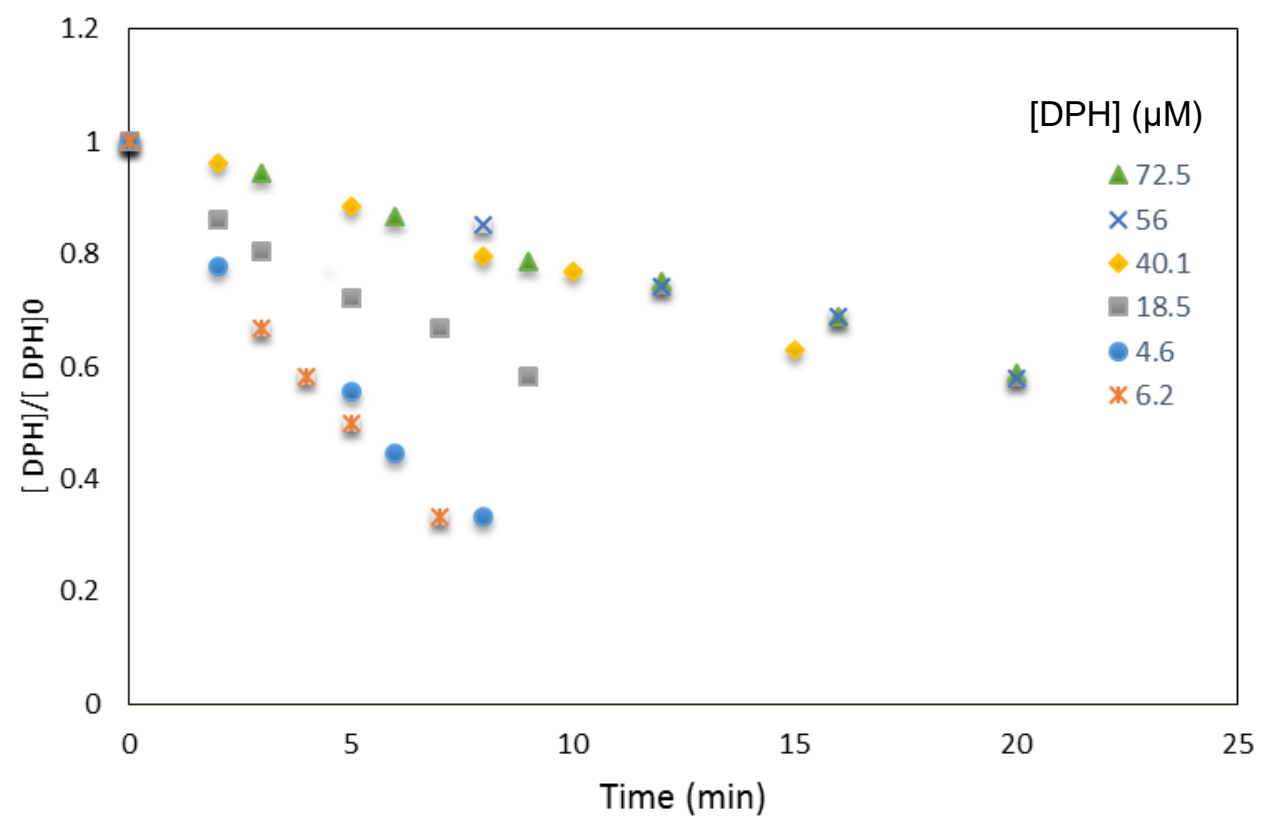

Figure 2.3 Removal of DPH during ultrasound treatment

Ultrasound leads to production of steady state concentration of ROS which will have a pronounced effect on overall degradation of the target compound. Therefore, when there is an excess number of DPH molecules, it is logical treatment times need to increase to generate more ROS to achieve complete degradation. 


\subsubsection{Kinetic studies}

Evaluation of reaction kinetics can provide useful mechanistic information and important parameters for the assessment and modeling of ultrasound treatment.

First order reaction and Langmuir-Hinshelwood kinetic model were applied to provide insight about the degradation process.

\section{Pseudo-first-order}

In previous studies, it was shown that ultrasonic assisted degradation follows the first order kinetics as shown below:

$$
\operatorname{In}\left(\frac{\mathrm{Ct}}{\mathrm{C} 0}\right)=-\mathrm{kt}
$$

Where $\mathrm{C}_{\mathrm{t}}$ is the concentration (at time $\mathrm{t}$ ) and $\mathrm{C}_{0}$ is the initial concentration (at time 0 ), and $\mathrm{k}$ is the first-order rate constant $\left(\mathrm{min}^{-1}\right)$. The first order rate constant $\mathrm{k}$ can be extracted from the slope of plot $\ln \left(\mathrm{C}_{t} / \mathrm{C}_{0}\right)$ as a function of reaction time.

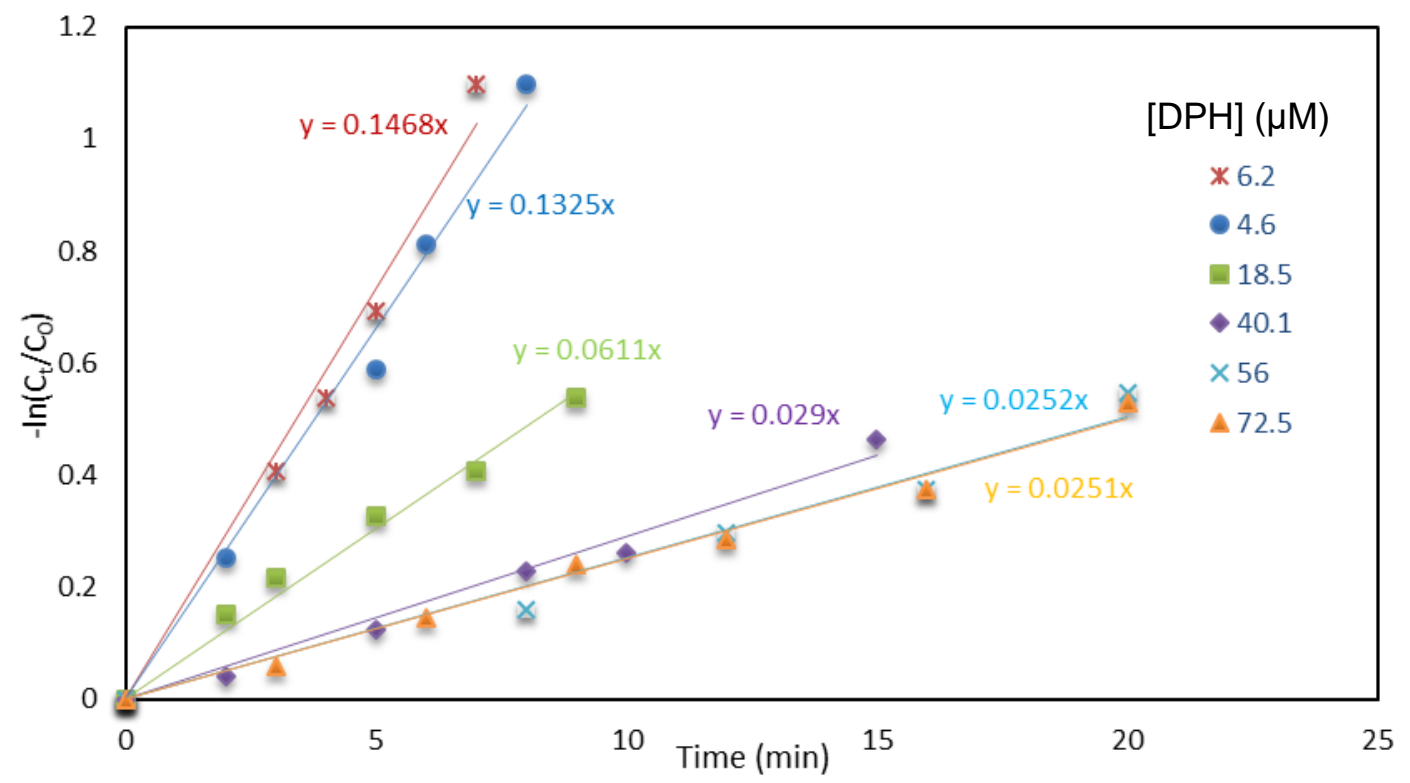

Figure 2.4 First-order plot under different DPH concentrations 
The observed first-order rate constants are $0.133 \mathrm{~min}^{-1}$ for $4.6 \mu \mathrm{M}, 0.147 \mathrm{~min}^{-1}$ for $6.2 \mu \mathrm{M}, 0.061 \mathrm{~min}^{-1}$ for $18.5 \mu \mathrm{M}, 0.029 \mathrm{~min}^{-1}$ for $40.1 \mu \mathrm{M}, 0.025 \mathrm{~min}^{-1}$ for $56.0 \mu \mathrm{M}$, $0.025 \mathrm{~min}^{-1}$ for $72.5 \mu \mathrm{M}$ (Table 2.2). The rate constant becomes constant as the concentration of $\mathrm{DPH}>40 \mu \mathrm{M}$ ), which indicates that the reaction system becomes saturated.

Table 2.2 Pseudo-first-order rate constants under different concentrations

\begin{tabular}{cc}
\hline \hline $\mathrm{DPH}](\mu \mathrm{M})$ & $k$ \\
\hline \hline 4.6 & 0.133 \\
6.2 & 0.147 \\
18.5 & 0.061 \\
40.1 & 0.029 \\
56.0 & 0.025 \\
72.5 & 0.025 \\
\hline \hline
\end{tabular}

\section{Langmuir- Hinshelwood}

Further analysis of the degradation process was achieved by employing kinetic models for interfacial process. Since the degradation process is heterogeneous, and can occur at the gas-liquid interface (at surface of cavitation bubble), the Langmuir-Hinshelwood kinetic model can be applied to provide insight about the degradation on localized substrate due to pyrolysis and degradation reactions from reactive oxygen species at the interface. 
The form of the Langmuir-Hinshelwood model is given as:

$$
\frac{1}{r_{0}}=\frac{1}{k_{r} K C_{0}}+\frac{1}{k_{r}}
$$

Where $\mathrm{r}_{0}$ is initial rate, $\mathrm{C}_{0}$ is the initial concentration of substrate. The value $\mathrm{kr}_{\mathrm{r}}$ is the reactivity coefficient, and $\mathrm{K}$ is the equilibrium constant.

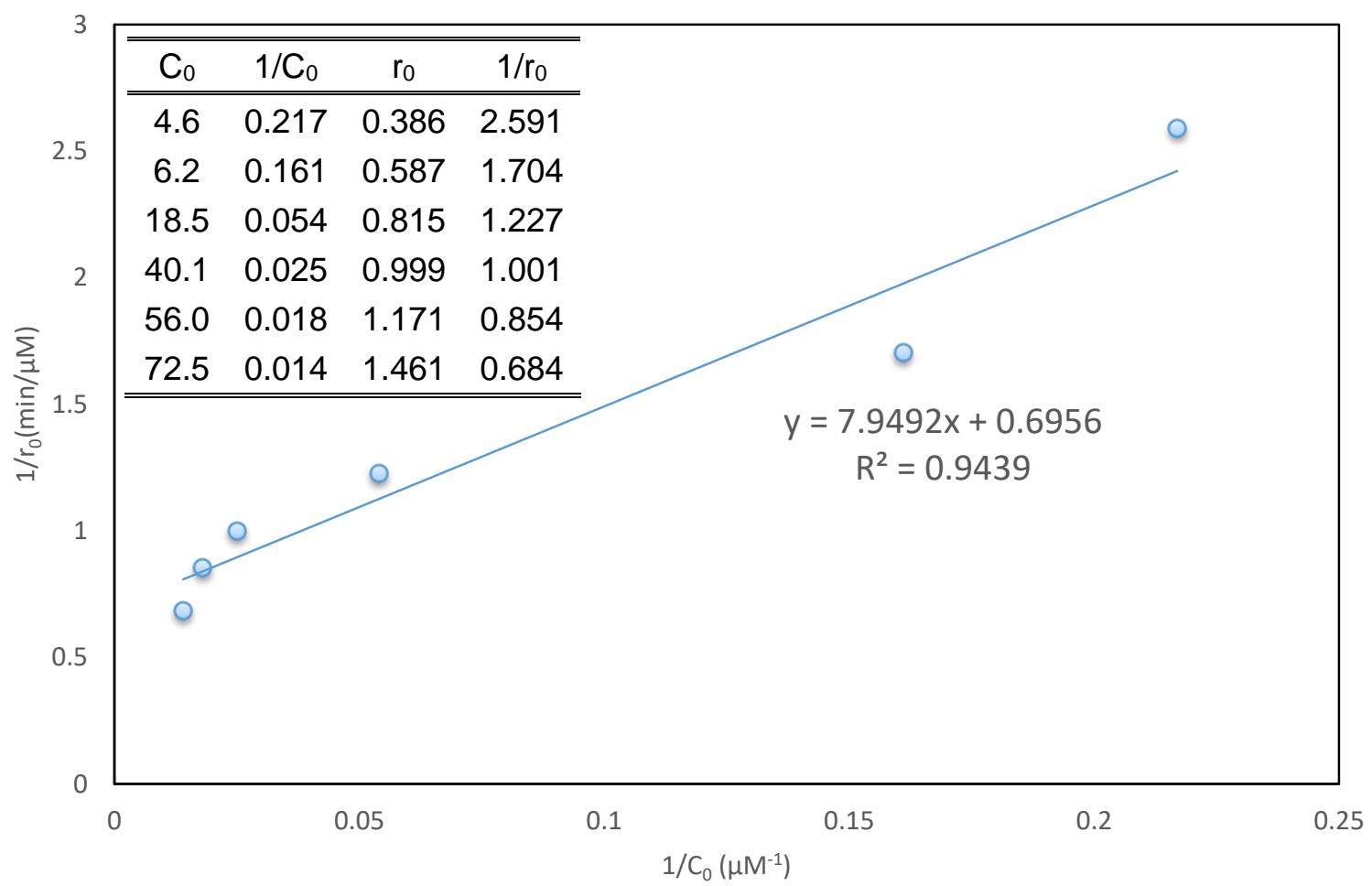

Figure 2.5 Langmuir- Hinshelwood plot of ultrasound treatment of DPH. The insert table is the initial rate at different concentrations of DPH and the inverse of them.

The Langmuir-Hinshelwood kinetic parameters $\mathrm{K}$ and $\mathrm{k}_{\mathrm{r}}$ were determined by the slope and intercept of plot $1 / \mathrm{r}_{0}$ as a function of $1 / \mathrm{C}_{0}$ (Figure 2.5), which yields $\mathrm{K}=$ $0.02 \mathrm{~L} / \mu \mathrm{M}$ and $\mathrm{Kr}=1.4 \mu \mathrm{M} / \mathrm{min} \cdot \mathrm{L}$ under our experimental conditions. The kinetic parameters obtained provide insight about both surface adsorption and oxidative reactivity. 


\subsection{Conclusion}

During ultrasonic cavitation, three zones are generated: hot spot, gas-liquid interface and bulk solution. The hot spot possesses extremely high pressure (100 atm) and temperature $(5000 \mathrm{~K})$, which will decompose $\mathrm{H}_{2} \mathrm{O}$ and $\mathrm{O}_{2}$ to produce reactive oxygen species (ROS). Reactive oxygen species play distinguishable roles in the degradation process. Once generated, ROS can diffuse to the interface and bulk solution which contains organic pollutants, subsequently leading to oxidative degradation of $\mathrm{DPH}$.

Our study demonstrated that DPH was effectively degraded under ultrasound treatment, and the concentration of DPH was critical and correlated to the initial rate constant during treatment. The process was most effective under relatively low concentrations, at which DPH could be degraded by $50 \%$ in the first $5 \mathrm{~min}$. The degradation process followed pseudo-first-order kinetics. The first-order rate constants were determined in the presence of different concentrations of DPH. The rate constants decrease as the concentrations of DPH increase and level off as the DPH reaches $>40 \mu \mathrm{M}$, which indicates that the reaction system is subject to saturation kinetics at higher concentrations. Finally, the Langmuir-Hinshelwood kinetic model was successfully applied and the parameters obtained ( $\mathrm{K}=0.02$ $\mathrm{L} / \mu \mathrm{M}$ and $\mathrm{Kr}=1.4 \mu \mathrm{M} / \mathrm{min} \cdot \mathrm{L}$ ) can provide insight about the degradation process at the gas-liquid surface. 
Our study leads to a better fundamental understanding of ultrasound induced degradation of $\mathrm{DPH}$, which demonstrated that ultrasound-induced degradation has great potential to serve as an effective method for treatment of aqueous media contaminated with DPH. Furthermore, the first order kinetic study provided in depth knowledge about the ultrasound assisted degradation, which can also help to predict the required reaction time to reach the treatment objective. The Langmuir-Hinshelwood kinetic model provide insight about the localization of DPH at the interface as well as the subsequent reactivity, which are critical in assessing practical water treatment technologies. 


\section{CHAPTER III.}

\section{CPO CATALYZED TRANSFORMATION OF ATORVASTATIN}

\subsection{Background}

Atorvastatin (ATV), also known as Lipitor (Figure 3.1), is one of the most commonly prescribed drugs in the US and Europe [51]. It inhibits the activity of hydroxymethylglutaryl-CoA (HMG-COA) involved in cholesterol biosynthesis, thus blocks the production of cholesterol. Atorvastatin has a molecular formula of $\mathrm{C}_{66} \mathrm{H}_{68} \mathrm{CaF}_{2} \mathrm{~N}_{4} \mathrm{O}_{10}$ with a molecular weight of $1155.34 \mathrm{~g} / \mathrm{mol}$. It is a white crystalline powder with a dissociation constant $(\mathrm{pKa})$ of 4.46 .

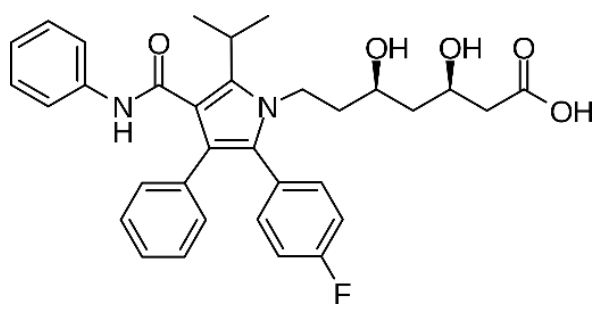

Figure 3.1 Chemical structure of ATV

The discovery of statins was a breakthrough in the prevention of hypercholesterolemia and related diseases. From 2002 to 2009, atorvastatin became the world's best-selling drug, with more than 9.3 billion dollars in sales during that time. The presence of ATV in sewage effluents and surface waters has been observed at concentrations of $\mathrm{mg} / \mathrm{L}$ levels [52]. Moreover, it has been detected in many water samples including treated sewage samples. When present to aquatic environments, ATV could be harmful to the aquatic ecosystem, adversely affecting aquatic organisms. 
The aim of this project was to investigate the potential application of CPO in the degradation of ATV. The rate of CPO in the degradation of ATV was measured. The CPO transformation of ATV was run at a range of $\mathrm{Cl}^{-}$and $\mathrm{Br}^{-}$concentrations, at buffered $\mathrm{pH}$, and over a range of concentrations of $\mathrm{H}_{2} \mathrm{O}_{2}$. The enzyme kinetics and degradation pathway were studied under the optimized conditions.

\subsection{Materials and methods}

\subsubsection{Materials}

Chloroperoxidase (CPO) was isolated and purified from Caldariomyces fumago according to the protocol reported by Morris and Hager [31]. Chloroperoxidase with Reinheitszahl value (Rz, purity index of heme enzymes) of 1.3 or higher was used for all experiments. The concentration of CPO was determined by measuring the absorbance at $398 \mathrm{~nm}$ using a molar extinction coefficient of $91,200 \mathrm{M}^{-1} \mathrm{~cm}^{-1}[31]$.

Atorvastatin was purchased from AK Scientific (Union City, CA, USA). All solvents used were purchased from Thermo Fisher Scientific Inc. (Waltham, MA, USA) and were of HPLC grade or Optima ${ }^{\circledR}$ LC/MS grade. Millipore Milli-Q water (18.2 M $\Omega$ ) was used throughout. 


\subsubsection{Sample preparation}

The reaction was conducted in a buffer solution with $100 \mathrm{mM} \mathrm{KH}_{2} \mathrm{PO}_{4}$ and $20 \mathrm{mM}$ $\mathrm{KBr}$ at $\mathrm{pH}$ 3.5. Atorvastatin was dissolved in methanol as the stock solution. $\mathrm{H}_{2} \mathrm{O}_{2}$ stock was prepared by diluting $35 \%$ concentrated $\mathrm{H}_{2} \mathrm{O}_{2}$ solution with buffer. Drug stock was added into the buffer solution to get a sufficient mix. The CPO stock solution was then added as a catalyst of the reaction. The $\mathrm{H}_{2} \mathrm{O}_{2}$ stock solution was subsequently added to initiate the reaction. Upon completion of the reaction, ethyl acetate was used to extract the filtrate and quench the reaction. The metabolites were extracted into the top organic layer during the liquid-liquid extraction while the CPO and salt in buffer remained in the aqueous layer. The top organic layer was separated and nitrogen gas was used to evaporate the organic solvent. The residues containing metabolites were then dissolved in different solvents for instrumental analysis. All samples were stored at $4{ }^{\circ} \mathrm{C}$ before measurements.

\subsubsection{UV-Visible spectrophotometry}

A VARIAN UV-Vis spectrophotometer (Cary 200 Bio) was used to record the optical data. The full scan mode was used to monitor the real-time absorbance change as a function of time. Using the spectra obtained under the full scan mode, the transformation from the reactant to products was observed. The kinetic parameters of the reaction were extracted by monitoring the absorbance change at a selected wavelength ( $241 \mathrm{~nm}$ for ATV) as a function of time. 


\subsubsection{UPLC-MS spectrophotometry}

Agilent 1290 Infinity UPLC system coupled with an orthogonal geometry Electrospray lonization (ESI) equipped Agilent 6530 Q-TOF mass spectrometer was used for the separation and identification of the metabolites. An Agilent ZORBAX Eclipse plus $\mathrm{C}_{18}$ Rapid Resolution High Definition (RRHD) column (3.0 $\times 100 \mathrm{~mm}, 1.8 \mu \mathrm{m}$ ) was applied, the column temperature was set at $30^{\circ} \mathrm{C}$. An infinity 1290 automatic injector was used to inject $1 \mu \mathrm{L}$ of the sample to the column. A flow rate of $0.4 \mathrm{~mL} / \mathrm{min}$ was used and an aqueous mobile phase $A$ consisting $5 \mathrm{mM}$ ammonium formate with $0.1 \%$ formic acid and the organic mobile phase B consisting of $90 \%$ acetonitrile and $10 \%$ water with $0.1 \%$ formic acid. The optimized chromatographic gradient was at 0 minute, $50 \% \mathrm{~A}$ and $50 \% \mathrm{~B}$ and $\mathrm{B}$ increased linearly to $95 \%$ over 6 minutes, this gradient was maintained for 4 minutes. Scanning was performed from $\mathrm{m} / \mathrm{z} 100$ to 1000 in the positive ion mode. The accurate mass of the molecular ions was processed using the Agilent MassHunter Qualitative Analysis software. 
3.3 Results and discussion

\subsubsection{Transformation of ATV by CPO}

The transformation of ATV catalyzed by CPO is monitored by UV-vis optical spectrophotometry. Atorvastatin showed a strong absorption at $241 \mathrm{~nm}$ as shown in Figure 3.2. The spectra of ATV with only $\mathrm{H}_{2} \mathrm{O}_{2}$ or $\mathrm{CPO}$ shows similar spectral features to ATV, indicating that no reaction occurs. However, the spectra of solution of ATV after addition of $\mathrm{H}_{2} \mathrm{O}_{2}$ or CPO shows a distinct decrease in $241 \mathrm{~nm}$ and a concomitant increase in $341 \mathrm{~nm}$. The change of the spectral clearly showed the transformation of ATV. Control groups of only $\mathrm{CPO}$ and $\mathrm{H}_{2} \mathrm{O}_{2}$ were also conducted to exclude the absorbance change caused by the addition of $\mathrm{H}_{2} \mathrm{O}_{2}$ and CPO.

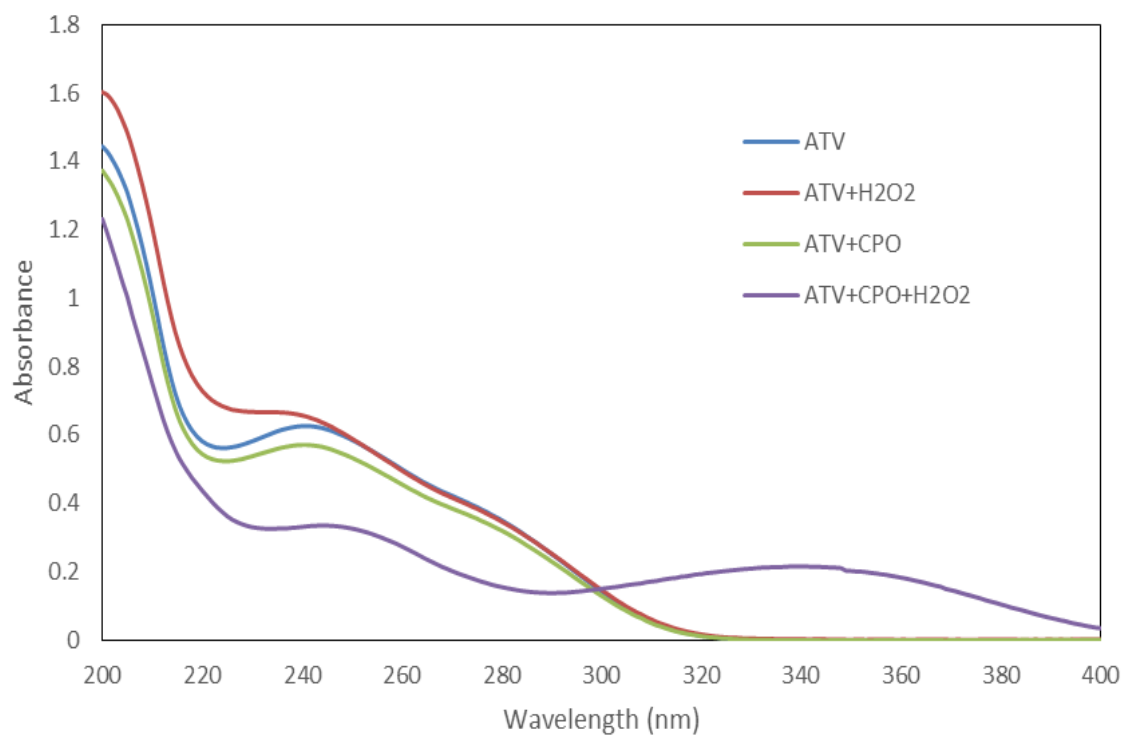

Figure 3.2 Transformation of ATV by CPO. ATV=8.66 $\mu \mathrm{M}, \mathrm{CPO}=4.8 \mathrm{nM}, \mathrm{H}_{2} \mathrm{O}_{2}=0.5 \mathrm{mM}$ Phosphate buffer: $100 \mathrm{mM} \mathrm{K}_{2} \mathrm{HPO}_{4}, 20 \mathrm{mM} \mathrm{KBr}$, pH 3.5 
The CPO-induced transformations of ATV at different time points are shown in Figure 3.3. The spectra was collected at 0, 40, 80, 120, 160 and $200 \mathrm{sec}$ after the reaction, including $25 \mathrm{sec}$ to collect data for full spectrum. The ATV spectra as a function of treatment time show an incremental decrease at $240 \mathrm{~nm}$, with the growth of a band at $341 \mathrm{~nm}$. Interestingly, an isosbestic point was observed around $300 \mathrm{~nm}$. This point indicated that at $\lambda=300 \mathrm{~nm}$, the UV absorbance of ATV and the generated products remained constant throughout the whole reaction. The conversion from the reactant to the product(s) is clearly indicated in the graph, providing fundamental information for further kinetic studies and product identification. The reaction rate decreases gradually reflected by the relative change in absorbance with time.

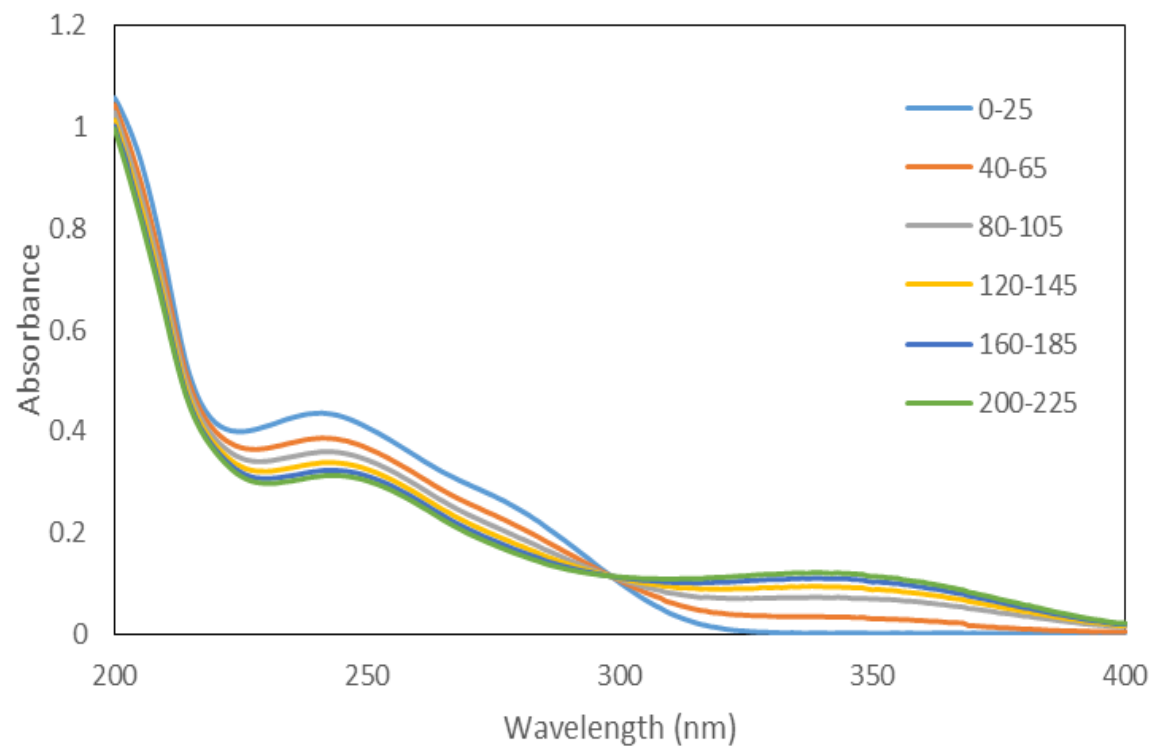

Figure 3.3 Transformation of ATV by CPO at different times. ATV $=8.66 \mu \mathrm{M}, \mathrm{CPO}=4.8 \mathrm{nM}$, $\mathrm{H}_{2} \mathrm{O}_{2}=0.5 \mathrm{mM}$ Phosphate buffer: $100 \mathrm{mM} \mathrm{K}_{2} \mathrm{HPO}_{4}, 20 \mathrm{mM} \mathrm{KBr}$, pH 3.5 


\subsubsection{The effect of $\mathrm{pH}$}

The effect of $\mathrm{pH}$ was investigated to determine the optimal $\mathrm{pH}$ for $\mathrm{CPO}$ catalyzed ATV transformation (Figure 3.4).

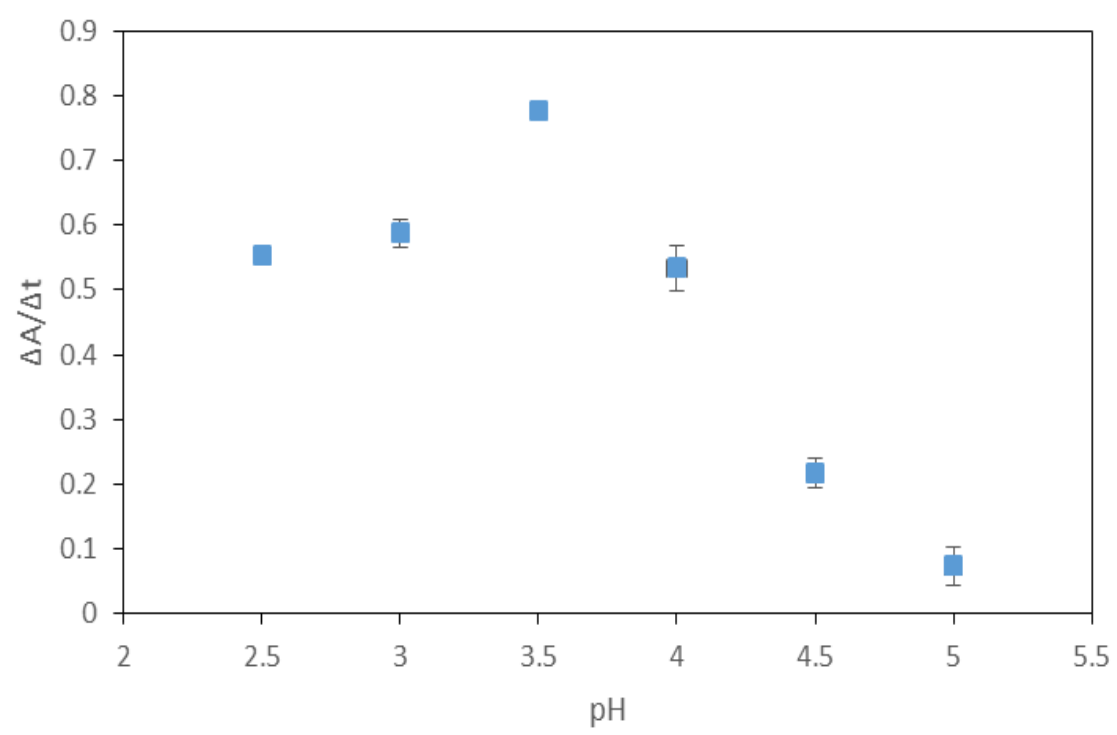

Figure 3.4 The effect of pH on ATV transformation

ATV $=8.66 \mu \mathrm{M}, \mathrm{CPO}=4.8 \mathrm{nM}, \mathrm{H}_{2} \mathrm{O}_{2}=0.5 \mathrm{mM}$ Phosphate buffer: $100 \mathrm{mM} \mathrm{K}_{2} \mathrm{HPO}_{4}, 20 \mathrm{mM} \mathrm{KBr}$, $\mathrm{pH} 2.5,3,3.5,4,4.5$ and 5 respectively. Monitored by $U V$ at $\lambda=241 \mathrm{~nm}$

The experiment was conducted in the $\mathrm{pH}$ range of 2.5-5.0. In the presence of 20 $\mathrm{mM} \mathrm{Br}$, the optimum $\mathrm{pH}$ for the transformation of ATV is 3.5. The transformation rate of ATV increased significantly with increasing $\mathrm{pH}$, and reached a maximum around $\mathrm{pH}$ 3.5. The degradation efficiency decreased sharply at $\mathrm{pH}>3.5$. This change indicated the transformation of ATV was a pH-dependent process, which could be attributed to the change in the protonation state of the ionizable group in compound $\mathrm{X}$ of $\mathrm{CPO}$. Compound $\mathrm{X}$ was reported to be involved in most CPO catalyzed halide dependent reactions [53], and releases the powerful oxidizing agent (HXO) under acidic conditions. 
3.3.3 The effect of hydrogen peroxide concentration

To determine the optium concentration of hydrogen peroxide, the experiment was carried out in the presence of varying concentrations of $\mathrm{H}_{2} \mathrm{O}_{2}$ (Figure 3.5).

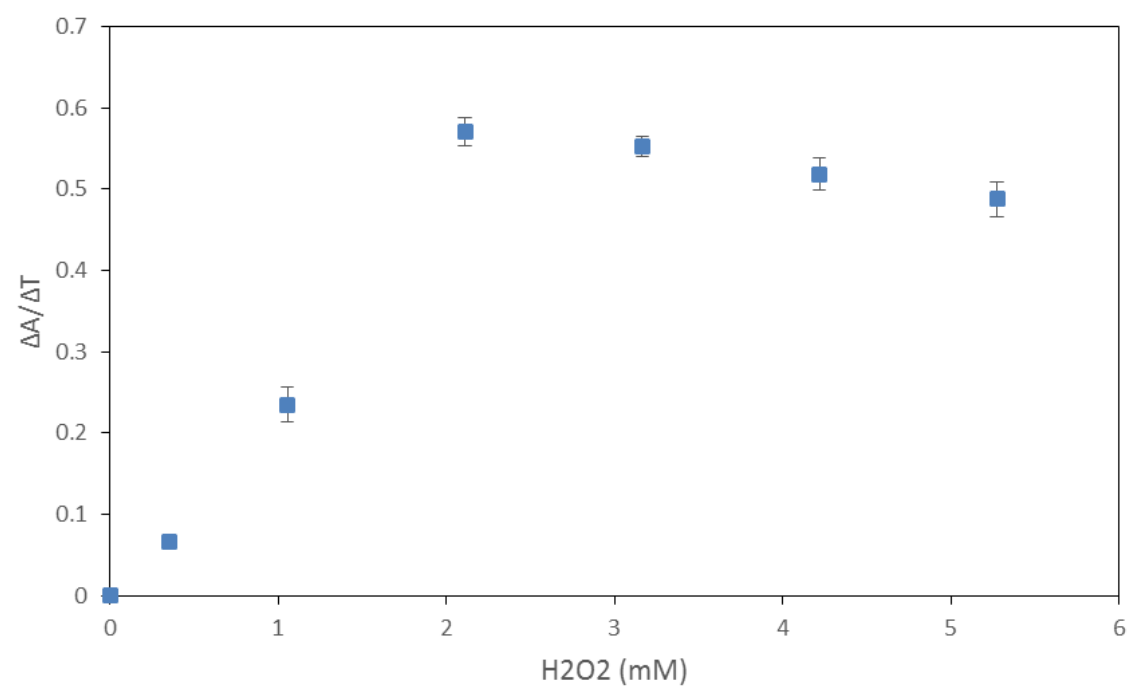

Figure 3.5 The effect of $\mathrm{H}_{2} \mathrm{O}_{2}$ concentration on ATV transformation $A T V=8.66 \mu \mathrm{M}, \mathrm{CPO}=4.8 \mathrm{nM}$, phosphate buffer: $100 \mathrm{mM} \mathrm{K}_{2} \mathrm{HPO}_{4}, 20 \mathrm{mM} \mathrm{KBr}, \mathrm{pH}=3.5$, $\mathrm{H}_{2} \mathrm{O}_{2}=0,0.35,1.06,2.11,3.17,4.22$ and $5.28 \mathrm{mM}$ respectively. Monitored by $U V$ at $\lambda=241 \mathrm{~nm}$ Control reaction showed the addition of $\mathrm{H}_{2} \mathrm{O}_{2}$ is required, and rate of transformation increased as the concentration of $\mathrm{H}_{2} \mathrm{O}_{2}$ increased up to $2 \mathrm{mM}$. The $\mathrm{H}_{2} \mathrm{O}_{2}$ concentrations above $2 \mathrm{~mm}$ decreased the transformation rate. One possible explanation is that excess $\mathrm{H}_{2} \mathrm{O}_{2}$ deactivates or degrades the enzyme. High concentrations of $\mathrm{H}_{2} \mathrm{O}_{2}$ have been reported to destroy the porphyrin prosthetic group in most heme containing enzymes [54]. Excess $\mathrm{H}_{2} \mathrm{O}_{2}$ may also inhibit the enzymatic process because of competition with halide ions required for the formation of compound X. A low concentration of $\mathrm{H}_{2} \mathrm{O}_{2}$ was applied for $\mathrm{CPO}$ induced transformation of ATV. 


\subsubsection{The effect of halide ions}

Since many of the reactions catalyzed by CPO are either dependent upon or accelerated by halide ions [55], it is vital to understand the effect of chloride $\left(\mathrm{Cl}^{-}\right)$ and bromide $(\mathrm{Br})$ ions. Figure 3.6 shows the relationship between the rate of ATV degradation and the ratio of $\mathrm{Cl}^{-}$or $\mathrm{Br}$ to ATV.
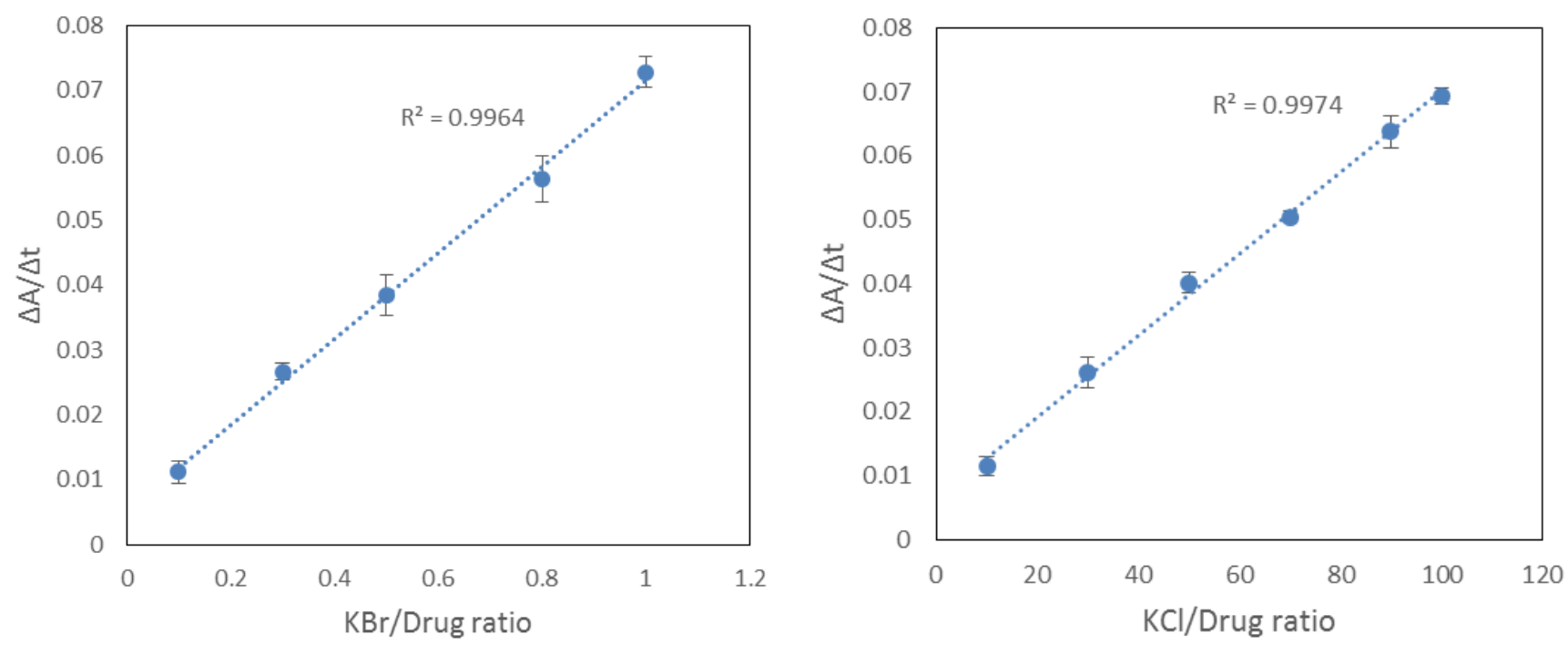

Figure 3.6 The effect of halide ions on ATV transformation ATV $=15 \mu \mathrm{M}, \mathrm{KBr}=1.5,4.5,7.5,12$ and $15 \mu \mathrm{M}$ respectively, $\mathrm{KCl}=0.15,0.3,0.75,1.05,1.35$ and 1.5 $\mathrm{mM}$ respectively, $\mathrm{CPO}=2.4 \mathrm{nM}, \mathrm{H}_{2} \mathrm{O}_{2}=15.5 \mu \mathrm{M}$ Monitored by $\mathrm{UV}$ at $241 \mathrm{~nm}$

There was no transformation observed without $\mathrm{Cl}^{-}$and $\mathrm{Br}^{-}$. Moreover, the transformation rate was proportional to the ion to drug ratio in a certain range (From 0.1-1 for $\mathrm{Br}^{-}$and 0.7-6.7 for $\mathrm{Cl}^{-}$). The transformation rate in the presence of $\mathrm{Br}^{-}$was more efficient when compared to $\mathrm{Cl}^{-}$. This could be attribute to the efficient distinction in the production of $\mathrm{HBrO}$ and $\mathrm{HClO}$ or their ability to oxidize ATV within CPO environment. 


\subsubsection{Product identification}

I used HPLC-MS to identify the products from CPO-catalyzed ATV transformation.

The results are shown below.
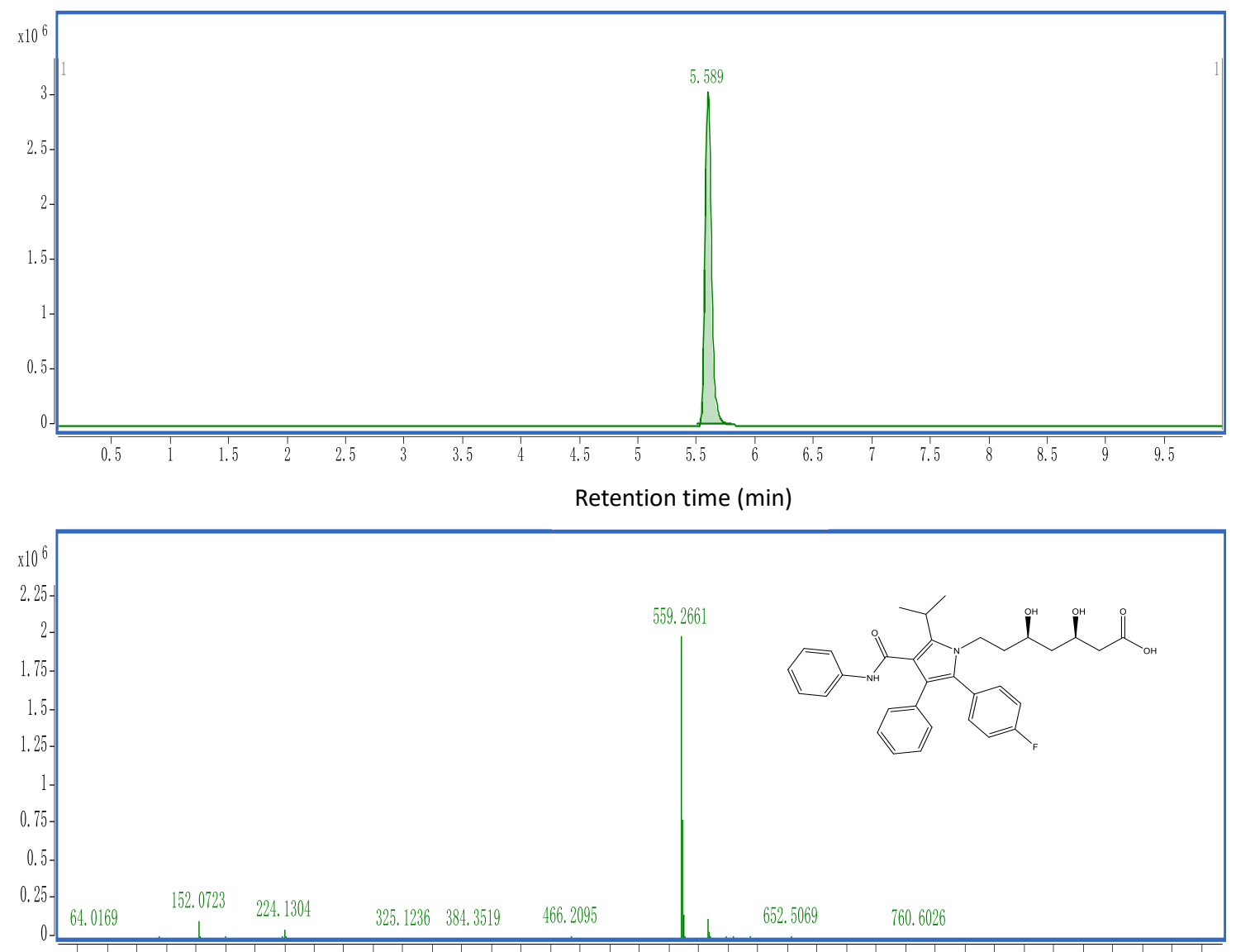

50751001251501752002252502753003253503754004254504755005255505756006256506757007257507758008258508759009259509751000

Mass to charge ratio $(\mathrm{m} / \mathrm{z})$

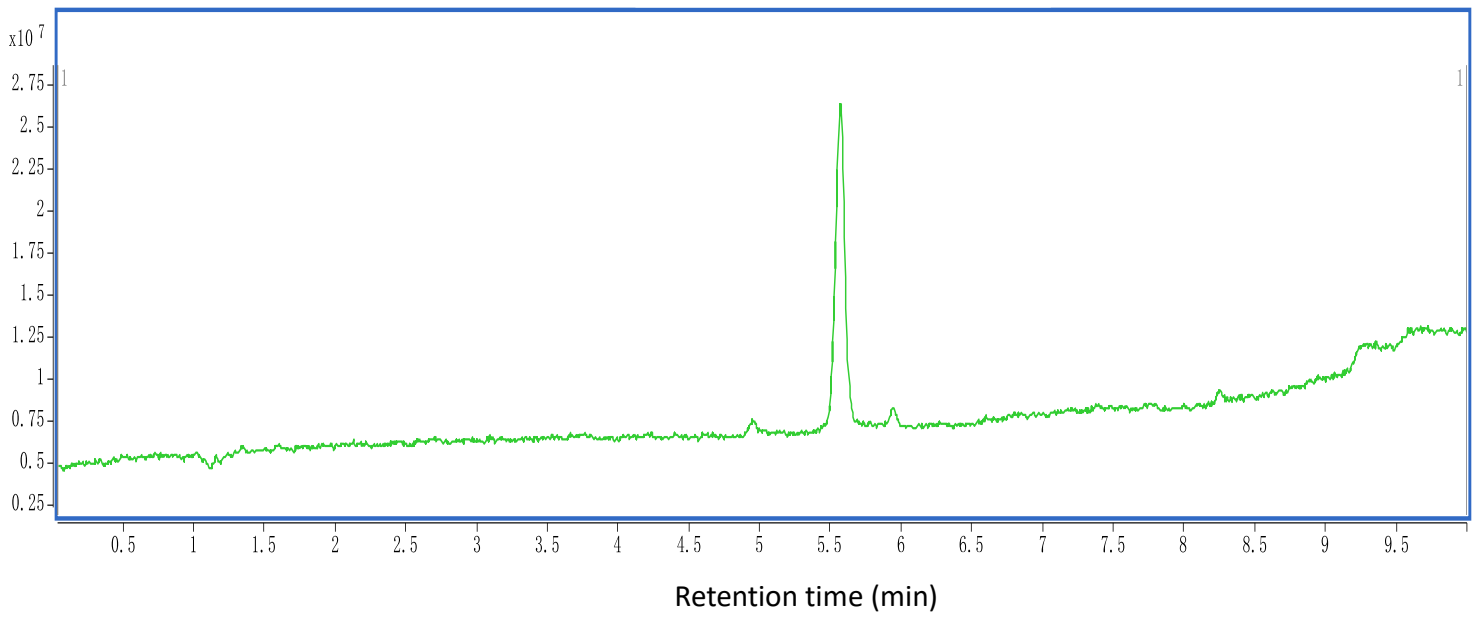

Figure 3.7 The chromatogram and MS spectra of ATV 


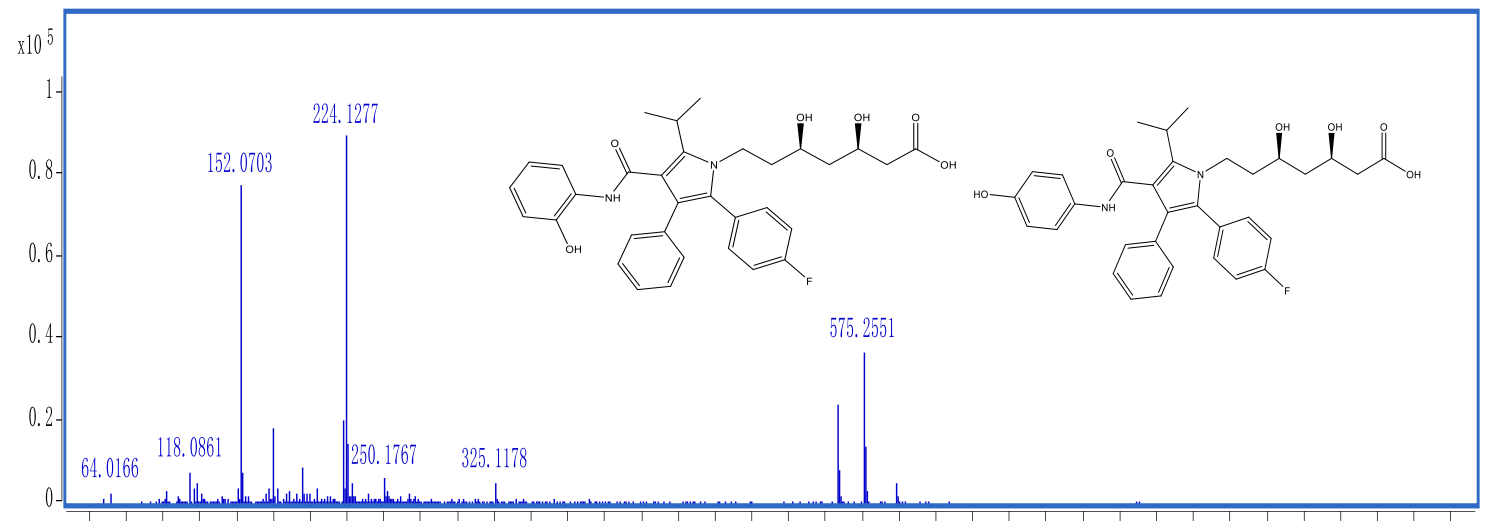

5075100125150175200225250275300325350375400425450475500525550575600625650675700725750775800825850875900925950975

Mass to charge ratio $(\mathrm{m} / \mathrm{z})$

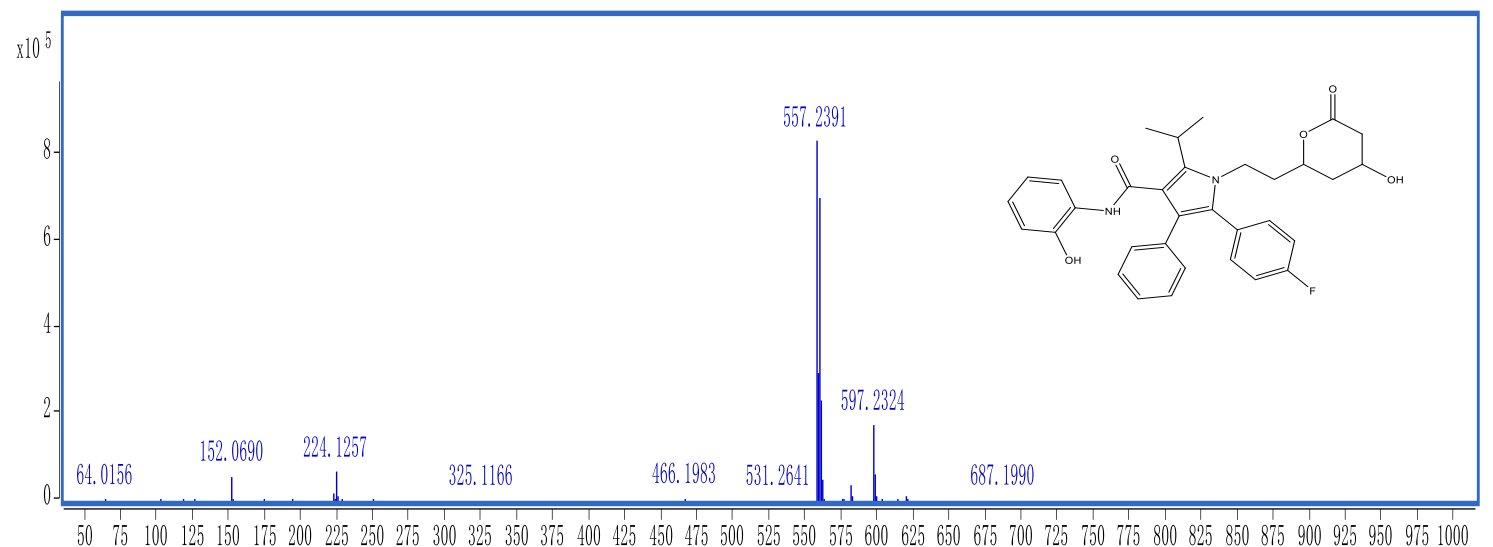

Mass to charge ratio $(\mathrm{m} / \mathrm{z})$

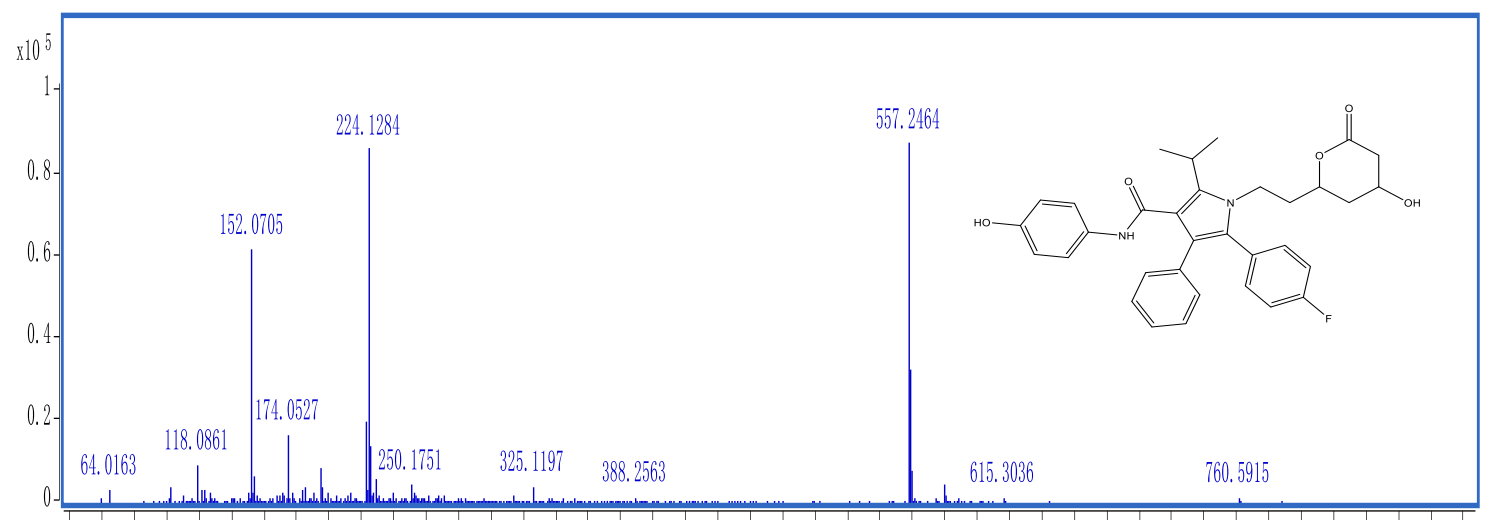

6080100120140160180200220240260280300320340360380400420440460480500520540560580600620640660680700720740760780800820840860880900

Mass to charge ratio $(\mathrm{m} / \mathrm{z})$

Figure 3.8 The chromatogram and MS spectra of metabolites 
From the chromatogram obtained, we can see there are three major peaks showing different retention times, suggesting the formation of putative products. When extracting the mass spectra from the middle peak (5.5 min), it shows a co-elution of two different substances, ATV at $\mathrm{m} / \mathrm{z} 559$ and one of the metabolites at $\mathrm{m} / \mathrm{z} 557$. The peak at 4.9 min was giving an ion at $\mathrm{m} / \mathrm{z} 575$, which indicates the hydroxylation of aromatic rings to the parent compound. The peak eluted at 5.9 min shows a molecular ion $[\mathrm{M}+\mathrm{H}]^{+}$at $\mathrm{m} / \mathrm{z} 557$, which has the same $\mathrm{m} / \mathrm{z}$ ratio as the peak eluted at $5.5 \mathrm{~min}$. This result indicated that there were two lactone isomers formed based on the $\mathrm{OH}$ substituted structure. Based on these observations, four metabolites from CPO catalyzed ATV transformation are proposed as listed in Table 3.1.

Table 3.1 Accurate-Mass LC-Q-TOF-MS data for the identification of ATV and its metabolites.

\begin{tabular}{|c|c|c|c|c|}
\hline Name & Formula & $\begin{array}{c}\text { Rentention time } \\
(\mathrm{min})\end{array}$ & $\begin{array}{c}\text { Experimental } \\
\text { mass }(\mathrm{m} / \mathrm{z})\end{array}$ & $\begin{array}{c}\text { Theoretical } \\
\mathrm{mass}(\mathrm{m} / \mathrm{z})\end{array}$ \\
\hline ATV & C33H35FN2O5 & 5.589 & 559.2661 & 558.2530 \\
\hline o-OH-ATV & C33H35FN2O6 & 4.937 & 575.2551 & 574.2479 \\
\hline p-OH-ATV & C33H35FN2O6 & 4.937 & 575.2551 & 574.2479 \\
\hline o-OH-ATV-lactone & C33H33FN2O5 & 5.553 & 557.2391 & 556.2374 \\
\hline p-OH-ATV-lactone & C33H33FN2O5 & 5.935 & 557.2464 & 556.2374 \\
\hline
\end{tabular}

The theoretical mass to charge ratios were calculated for ATV and its metabolites as a reference to their experimental values. These products were confirmed by different retention times and accurate mass-to-charge ratios. For hydroxylated metabolites, the isomer's peak were detected at the same retention time, while for hydroxylated lactone metabolites the retention times were different. 
3.3.6 Mechanism of CPO-catalyzed ATV transformation

On the basis of LC-MS and UV-Vis spectroscopic studies, the mechanism of CPO-catalyzed transformation of ATV is proposed (Figure 3.9).

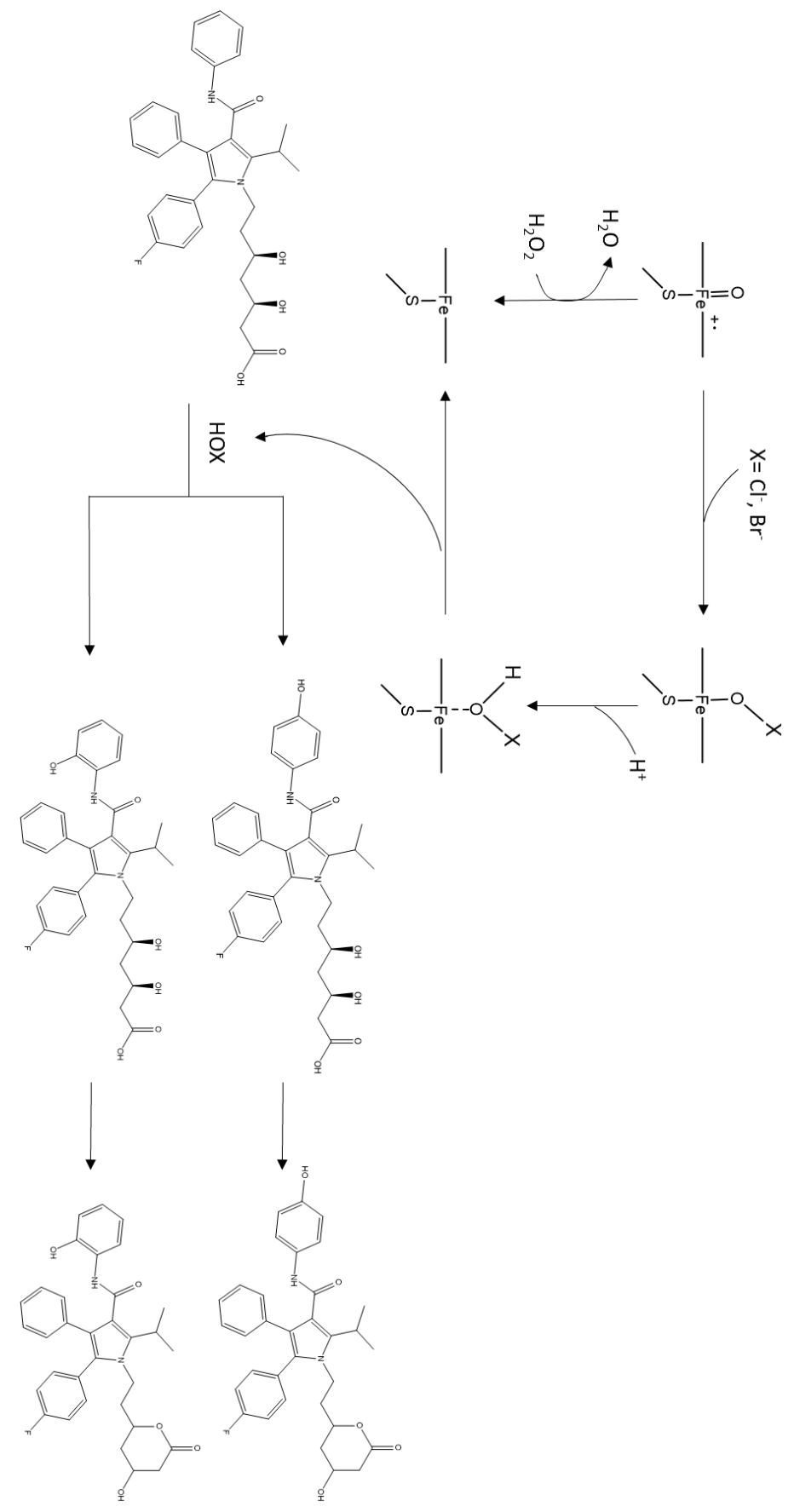

Figure 3.9 Proposed mechanism of ATV transformation $(\mathrm{C}=\mathrm{Cl}$ or $\mathrm{Br})$ 


\subsection{Conclusion}

In summary, we found that CPO readily transformed ATV over a range of acidic solutions ( 2.5 to 5 ) with the fastest transformation observed at $\mathrm{pH}=3.5$. A range of $\left[\mathrm{H}_{2} \mathrm{O}_{2}\right]$ was tested and the maximum rate was achieved when $\mathrm{H}_{2} \mathrm{O}_{2}$ concentration reached $2.11 \mathrm{mM}$. However, further addition of $\mathrm{H}_{2} \mathrm{O}_{2}$ repressed the transformation possibility because of deactivation of the enzyme caused by high concentration of $\mathrm{H}_{2} \mathrm{O}_{2}$. The important role halide ion played in CPO catalyzed transformation of ATV was demonstrated; although, no halogenated products are identified. Bromide ion was shown to be more potent in CPO catalyzed transformation of ATV than chloride ion, which could be attributed to the different binding affinity of $\mathrm{Cl}^{-}$or $\mathrm{Br}^{-}$to $\mathrm{CPO}$.

The LC-MS analysis proved to be an efficient technique for determining the metabolites of ATV. My result is in good agreement with the reported mechanism of ATV transformation [56]. Atorvastatin and its major hydroxylated metabolites, 2-ATV and 4-ATV, are present in equilibrium with their corresponding inactive lactone forms. The mechanism proposed includes the formation of an oxoferryl $\pi$-cation radical intermediate (compound I), and a hypohalite adduct (compound $\mathrm{X})$. The $\mathrm{pH}$ dependent experiment suggests the protonation of compound $\mathrm{X}$ under acidic conditions, which can release HOX from the active site and subsequently reacts with ATV to initiate an electrophilic attack. 
The study provided a fundamental understanding of enzymatic based transformation of ATV. The effect of halide ion and $\mathrm{pH}$ helps our understanding of how environmental factors would affect the degradation in real application. Identification of products shed light into understanding of the characteristic of CPO-catalyzed reactions. Based on the proposed degradation pathway, the associated toxicity of intermediates/products can be studied to assess their impact on environment. These studies provided in depth knowledge about the enzymatic degradation, which are critical for environmental friendly water treatment technologies. 


\section{CHAPTER IV.}

\section{CPO CATALYZED TRANSFORMATION OF ROXARSONE}

\subsection{Background}

Roxarsone (ROX), 4-hydorxy-3-nitrobenzenearsenic acid (Figure 4.1), is used as a common feed additive in poultry industry. It is a derivative of phenylarsonic acid as it has an arsenic directly linked to a benzene ring. Roxarsone is used to improve feed efficiency and increase weight gain in chicken and pigs. Figure 4.2 shows how ROX is introduced into the environment. Roxarsone is a threat to humans since arsenic species has been recognized as a toxic metalloid presented in rivers [57] with a high solubility in water.<smiles>O=[N+]([O-])c1cc([As](=O)(O)O)ccc1O</smiles>

Figure 4.1 Chemical structure of Roxarsone (ROX)
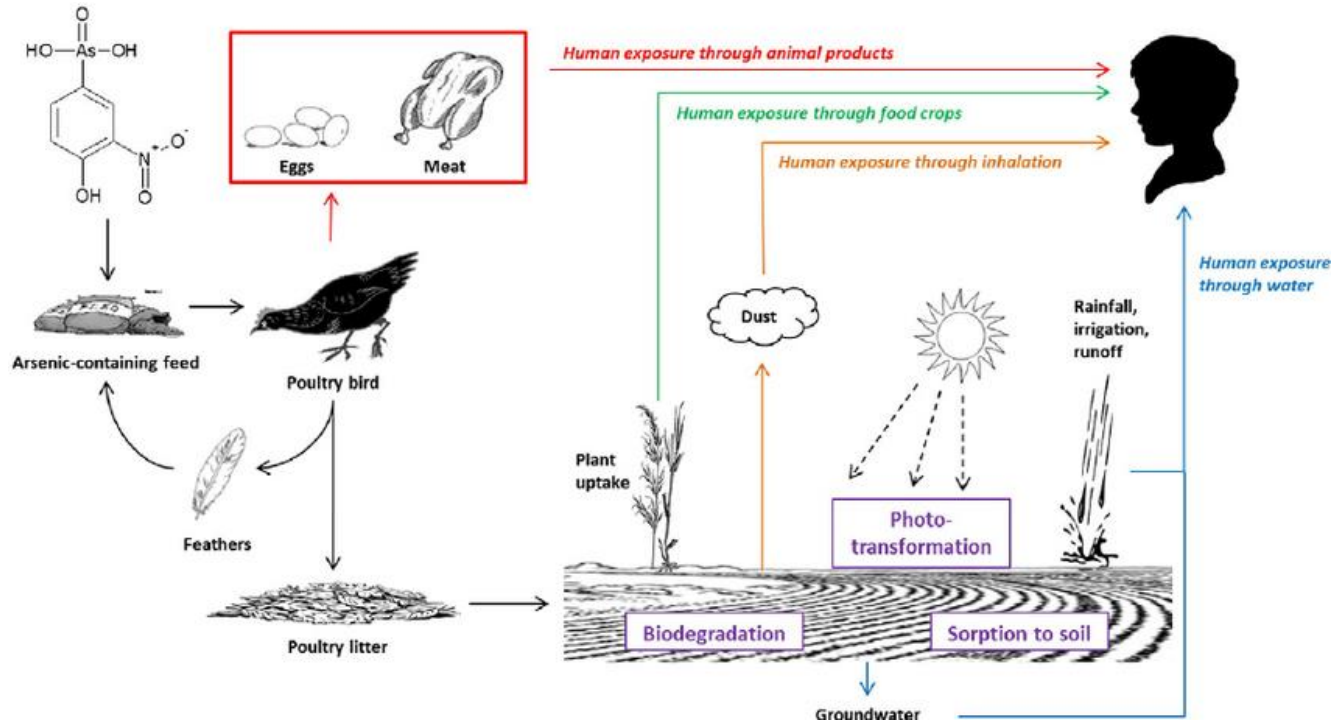

Figure 4.2 Fate of ROX used as feed additives [58] 
Studies have shown that arsenic is readily released to surface and ground water from poultry litter [58], leading to a serious ROX pollution problem. With the development of nanotechnology, the adsorption of ROX in aqueous solution was investigated [59], however, this technique has limitations for drinking water. AOPs have been used in the treatment of organoarsenicals like ROX [60, 61]. Hydroxyl radical mediated processes lead to the degradation of ROX however the non-selective nature of $\mathrm{OH}$. is a problem for practical applications. Furthermore, advanced oxidation treatment drives transformation of organoarsenicals to inorganic forms As $(\mathrm{V})$ which requires removal to prevent arsenic presence in discharged agricultural wastewater.

The goal of this study was to examine the potential effectiveness of CPO-based enzymatic transformation for the removal of ROX. The solution $\mathrm{pH}$, the concentration of halide ion and the concentration of $\mathrm{H}_{2} \mathrm{O}_{2}$ were varied to identify optimal conditions. Detailed kinetic and product studies were carried out under optimal conditions. The major-products were identified, and the mechanism of ROX transformation was proposed. 
4.2 Materials and methods

\subsubsection{Materials}

Chloroperoxidase (CPO) was isolated and purified from Caldariomyces fumago according to the protocol reported by Morris and Hager [31]. CPO with Rz of 1.3 or higher was used for all experiments. The concentration of CPO was determined by measuring the absorbance at $398 \mathrm{~nm}$ using a molar extinction coefficient of $91,200 \mathrm{M}^{-1} \mathrm{~cm}^{-1}[56]$.

Roxarsone was purchased from Tokyo Kasei Kogyo Co., Ltd, (Tokyo, Japan). All other chemicals and solvents were purchased from Thermo Fisher Scientific (Waltham, MA, USA) and are of either reagent or analytical grade. All aqueous solutions were prepared with Millipore filtered water (18.2 M 2$)$ and volumetric lab equipment.

\subsubsection{Sample preparation}

The reaction was conducted in $100 \mathrm{mM} \mathrm{KH}_{2} \mathrm{PO}_{4}$ buffer containing $20 \mathrm{mM} \mathrm{KBr}$ at pH 3.5. Roxarsone was dissolved in buffer as the stock solution. $\mathrm{H}_{2} \mathrm{O}_{2}$ stock was prepared by diluting $35 \%$ concentrated $\mathrm{H}_{2} \mathrm{O}_{2}$ solution into the buffer solution. Roxarsone stock was added into the buffer solution and mixed thoroughly. The CPO stock solution was then added as a catalyst of the reaction. The $\mathrm{H}_{2} \mathrm{O}_{2}$ stock solution was subsequently added to initiate the reaction. Upon completion of the reaction, ethyl acetate was used to extract the products and quench the reaction. 
During extraction, the metabolites were extracted into the top organic layer during the liquid-liquid extraction while CPO and salt remained in the bottom aqueous layer. The top organic layer was separated and nitrogen gas was used to evaporate the solvent. The residues containing metabolites were dissolved in different solvents for instrumental analysis. Samples were stored at $4{ }^{\circ} \mathrm{C}$ before use.

\subsubsection{UV-Visible spectrophotometry}

A VARIAN UV-Vis spectrophotometer (Cary 200 Bio) was used to monitor the progress of the reaction. The full scan mode was used to monitor the real-time absorbance change as a function of time. Based on the spectra obtained under the full scan mode, the conversion of the reactant to products was observed. To determine the rate of ROX degradation, the kinetic mode was used to monitor the absorbance change at a selected wavelength ( $223 \mathrm{~nm}$ for ROX) as a function of time. The rate was calculated according to the equation below:

$$
\operatorname{Rate}(\mu \mathrm{M} / \mathrm{min})=\frac{A_{0}-A_{t}}{0.1087 \times\left(t_{0}-t_{t}\right)}
$$

$A_{0}$ is the absorbance monitored at time to, $A_{t}$ is the absorbance monitored at time $\mathrm{t}$, and $0.1087\left(\mu \mathrm{M}^{-1} \mathrm{~cm}^{-1}\right)$ is the measured extinction coefficient of ROX at 223 $\mathrm{nm}$. 


\subsubsection{NMR characterization}

Nuclear magnetic resonance (NMR) spectroscopy were employed to identify the major transformation products. The NMR experiments were carried out on a Bruker $400 \mathrm{MHz}$ NMR spectrometer operating at a proton frequency of 400.13 $\mathrm{MHz}$. The samples were all dissolved in deuterated solvents before transferring to $5 \mathrm{~mm}$ NMR tubes. All spectra were recorded at $298 \mathrm{~K}$ using standard pulse programs from the manufacturer.

\subsubsection{Mass Spectrometry}

A volume of $100 \mu \mathrm{L}$ of the sample was mixed with $10 \mu \mathrm{L}$ of Agilent ESI tuning solution ( $\mathrm{p} / \mathrm{n}$ G2421-60001; L/N A117489) and $890 \mu \mathrm{L}$ of acetonitrile, for a final concentration of $1 \mathrm{mg} / \mathrm{L}$. A blank was prepared similarly, using $100 \mu \mathrm{L}$ of acetone (OptimaTM grade) instead of the sample. Using a syringe pump (3 $\mu \mathrm{L} / \mathrm{min})$, the obtained solution was infused into the Turbo VTM ESI source of an AB SCIEX QTRAP $5500 \AA$ triple quadrupole mass spectrometer operating in full scan $(100-650 \mathrm{Da})$ in negative mode. Product ion scan (Target $\rightarrow 50-300 \mathrm{Da})$ was performed at medium collision gas pressure and at $40 \mathrm{eV}$ of collision energy. 
4.3 Results and discussion

\subsubsection{Transformation of ROX by CPO}

The transformation of ATV catalyzed by CPO is shown in Figure 4.3. Roxarsone showed a strong absorption at $223 \mathrm{~nm}$. With the addition of only $\mathrm{H}_{2} \mathrm{O}_{2}$ or $\mathrm{CPO}$, the spectral pattern remains essentially unchanged, indicating no reaction occurs. When $\mathrm{H}_{2} \mathrm{O}_{2}$ and $\mathrm{CPO}$ were mixed together with $\mathrm{ROX}$, a distinct spectrum was observed, with a decrease in $223 \mathrm{~nm}$ and a concomitant increase in $400 \mathrm{~nm}$. The change of the spectral pattern clearly showed the transformation of ROX to products. Control groups of only $\mathrm{CPO}$ and $\mathrm{H}_{2} \mathrm{O}_{2}$ were also conducted to exclude the absorbance change due to addition of $\mathrm{H}_{2} \mathrm{O}_{2}$ and CPO.

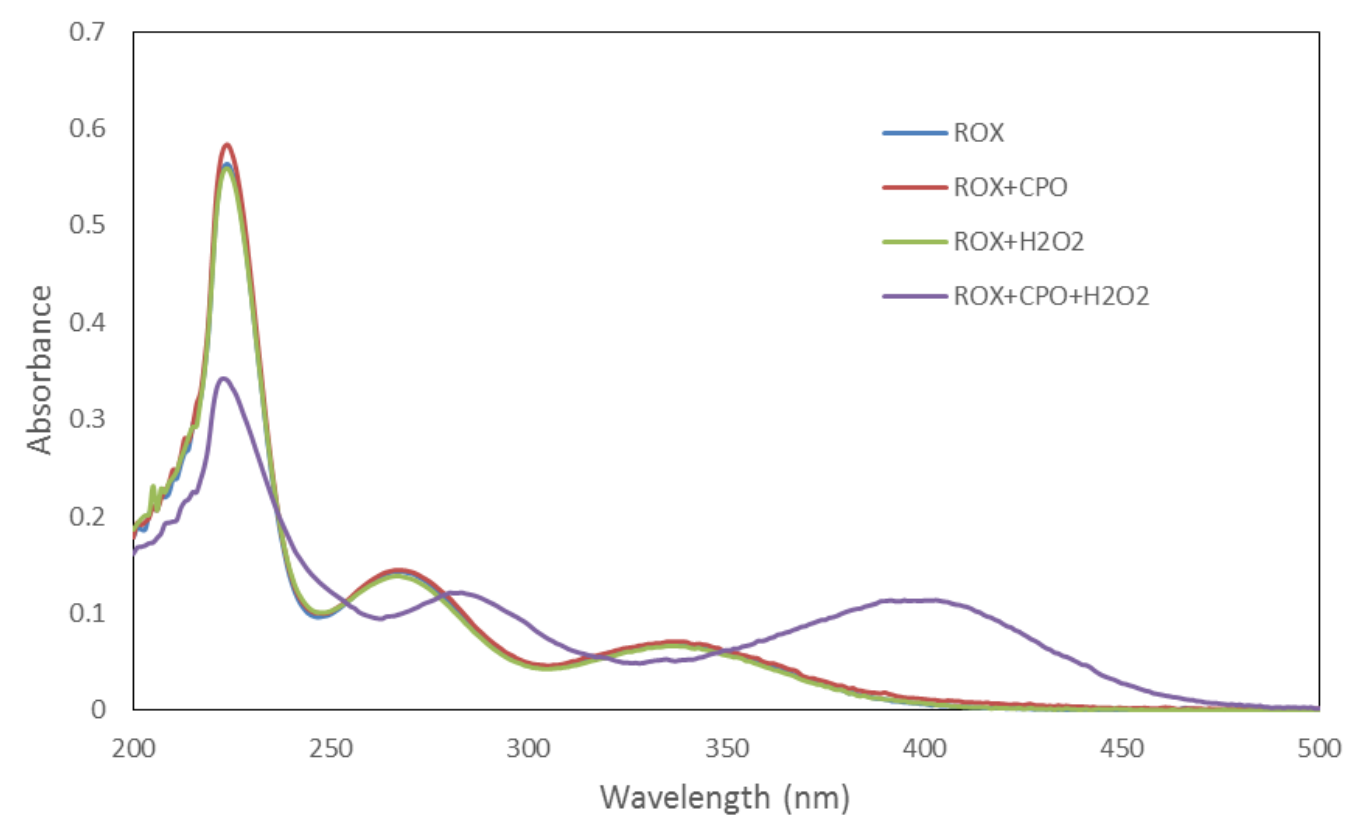

Figure 4.3 Transformation of ROX by CPO. $\mathrm{ROX}=25 \mu \mathrm{M}, \mathrm{CPO}=4.8 \mathrm{nM}, \mathrm{H}_{2} \mathrm{O}_{2}=0.31 \mathrm{mM}$ Phosphate buffer: $100 \mathrm{mM} \mathrm{K}_{2} \mathrm{HPO}_{4}, 20 \mathrm{mM} \mathrm{KBr}$, pH 3.5 


\subsubsection{The effect of $\mathrm{pH}$}

The effect of $\mathrm{pH}$ was investigated to determine the optimal $\mathrm{pH}$ for $\mathrm{CPO}$ catalyzed ROX transformation (Figure 4.4).

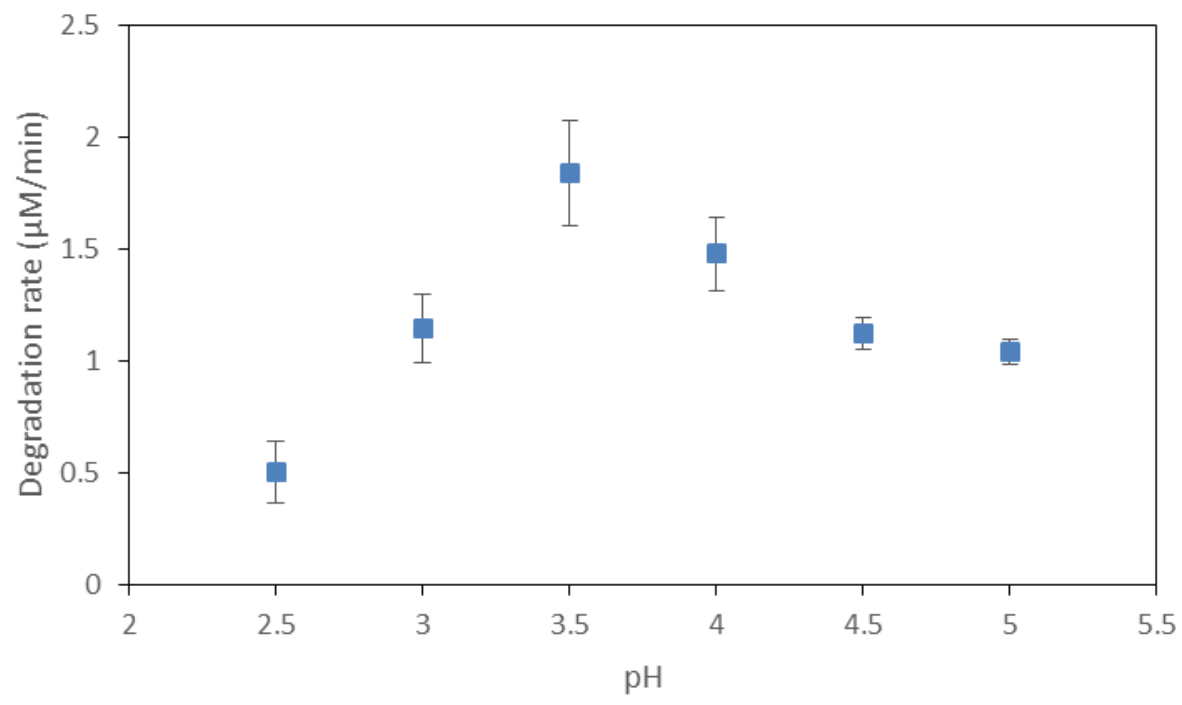

Figure 4.4 The effect of $\mathrm{pH}$ on ROX transformation

$\mathrm{ROX}=25 \mu \mathrm{M}, \mathrm{CPO}=4.8 \mathrm{nM}, \mathrm{H} 2 \mathrm{O} 2=0.69 \mathrm{mM}$ Phosphate buffer: $100 \mathrm{mM} \mathrm{K} 2 \mathrm{HPO} 4,20 \mathrm{mM} \mathrm{KBr}$, $\mathrm{pH} 2.5,3,3.5,4,4.5$ and 5 respectively. Monitored by UV at $\lambda=223 \mathrm{~nm}$

The experiment was conducted in the $\mathrm{pH}$ range of 2.5-5.0. In the presence of 20 $\mathrm{mM} \mathrm{Br}$, the optimum $\mathrm{pH}$ for the transformation of $\mathrm{ROX}$ is 3.5. The transformation rate gradually increased when $\mathrm{pH}$ increased from 2.5 to 3.5 and decresed from 3.5 to 5.0. This trend indicated that the transformation of ROX was a $\mathrm{pH}$-dependent process, which could be attribute to the change in the protonation state of the ionizable group in conpound $X$. Compound $X$ was reported to be involved in most CPO catalyzed halide dependent reactions [53], and was able to release the powerful oxidizing agent $(\mathrm{HXO})$ under acidic conditions. 


\subsubsection{The effect of hydrogen peroxide concentration}

To examine the effect of $\mathrm{H}_{2} \mathrm{O}_{2}$ concentration on the transformation of $\mathrm{ROX}$, the experiment was carried out in the presence of varying concentrations of $\mathrm{H}_{2} \mathrm{O}_{2}$ (Figure 4.5).

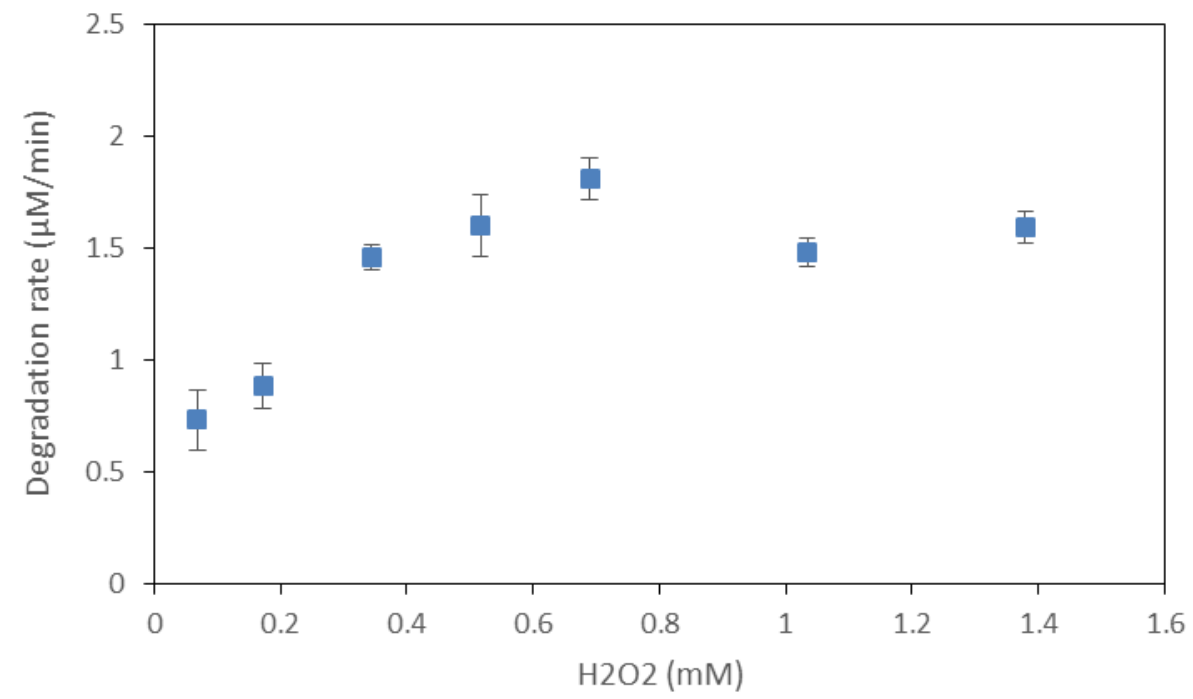

Figure 4.5 The effect of $\mathrm{H}_{2} \mathrm{O}_{2}$ concentration on ATV transformation $\mathrm{ROX}=25 \mu \mathrm{M}, \mathrm{CPO}=4.8 \mathrm{nM}$, phosphate buffer: $100 \mathrm{mM} \mathrm{K}_{2} \mathrm{HPO}_{4}, 20 \mathrm{mM} \mathrm{KBr}, \mathrm{pH}=3.5$, $\mathrm{H}_{2} \mathrm{O}_{2}=0,0.07,0.17,0.34,0.52,0.69,1.03$ and $1.38 \mathrm{mM}$ respectively. Monitored by UV at $\lambda=223 \mathrm{~nm}$

As expected, there is no transformation observed without the addition of $\mathrm{H}_{2} \mathrm{O}_{2}$.

The rate of transformation is greatly enhanced as the concentration of $\mathrm{H}_{2} \mathrm{O}_{2}$ increased up to $0.69 \mathrm{mM}$. However, further increase in $\mathrm{H}_{2} \mathrm{O}_{2}$ concentration (from 0.69 to $1.38 \mathrm{mM}$ ) decreased the reaction rate. The possible explanation could be that excess $\mathrm{H}_{2} \mathrm{O}_{2}$ deactivates the enzyme by forming a highly reactive iron peroxyl species which leads to heme degradation [62]. Thus, low concentrations of $\mathrm{H}_{2} \mathrm{O}_{2}$ is applied for CPO induced transformation of ROX. 


\subsubsection{Michaelis-Menten kinetics}

CPO-catalyzed degradations generally follow Michaelis-Menten kinetics, an established model of single substrate kinetics showing the relation between the substrate concentration and reaction rate. The form of Michaelis-Menten equation is given as:

$$
\mathrm{V}=\frac{V_{\max } \times[S]}{K_{m}+[S]}
$$

Where $\mathrm{S}$ is the concentration of the substrate $(\mathrm{ROX}), \mathrm{V}$ is the initial reaction rate measured in the linear range of transformation. $V_{\max }$ is the maximum rate that can be achieved by the system and $\mathrm{K}_{\mathrm{m}}$ is the substrate concentration at which the reaction rate is half of $V_{\max } . \mathrm{K}_{\mathrm{m}}$, known as the Michaelis constant, indicates the affinity of the substrate to the enzyme, and the value depends on both of them, as well as conditions such as $\mathrm{pH}$ and temperature.

$$
\frac{1}{V}=\frac{K_{m}}{V_{\max }} \times \frac{1}{[S]}+\frac{1}{V_{\max }}
$$

Figure 4.6 Lineweaver-Burk plot

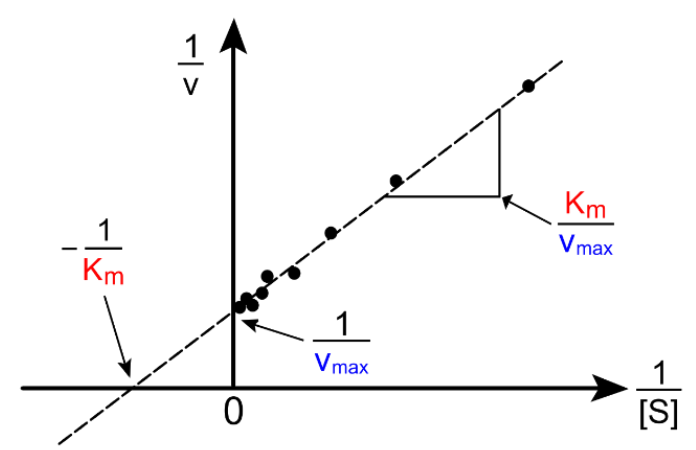

Lineweaver-Burk plot was used to calculate Michaelis-Menten constant $\left(\mathrm{K}_{\mathrm{m}}\right)$ and maximum reaction rate $\left(V_{\max }\right)$. Plotting the inverse of substrate concentration and initial rate, yields a straight line that permits the determination of $K_{m}$ and $V_{\max }$. 
To conduct the experiment, different concentrations of ROX were dissolved in the buffer solution. Initial transformation rates were calculated by monitoring absorbance at $223 \mathrm{~nm}$ from $12-24$ seconds.

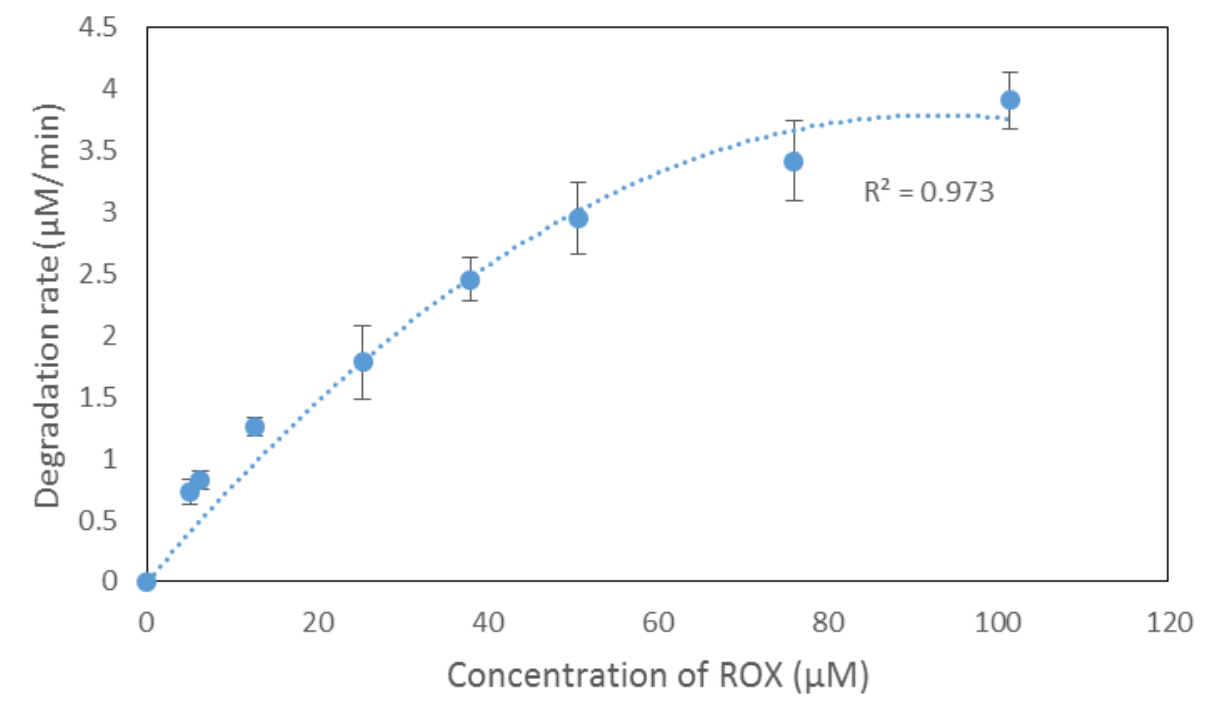

Figure 4.7 Michaelis-Menten kinetics

$\mathrm{CPO}=4.8 \mathrm{nM}, \mathrm{H}_{2} \mathrm{O}_{2}=0.69 \mathrm{mM}$, phosphate buffer: $100 \mathrm{mM} \mathrm{K}_{2} \mathrm{HPO}_{4}, 20 \mathrm{mM} \mathrm{KBr}, \mathrm{pH}=3.5$, $\mathrm{ROX}=0,5.1,6.3,12.7,25.3,38.0,50.7,76.0$, and $101.4 \mu \mathrm{M}$ respectively.

Monitored by UV at $\lambda=223 \mathrm{~nm}$

From the plot, the kinetic parameter were obtained with a Michaelis-Menten

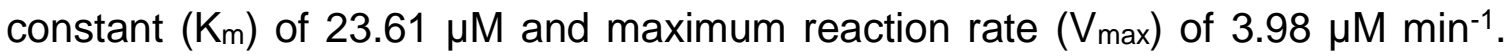
Based on the parameter calculated, turnover number can be determined to give the maximum number of conversions of substrate molecules per second that a single catalytic site will execute for a given enzyme concentration.

$$
k_{\text {cat }}=\frac{V_{\max }}{[E]_{T}}
$$

$V_{\max }$ is the maximum rate and $[E]_{T}$ is the concentration of catalyst (CPO). 


\subsubsection{Product identification}

NMR and mass analyses were employed to establish the structure of the products from CPO-catalyzed transformation of ROX. The proton NMR spectra are shown in Figure 4.8. The mass spectra are shown in Figure 4.9.
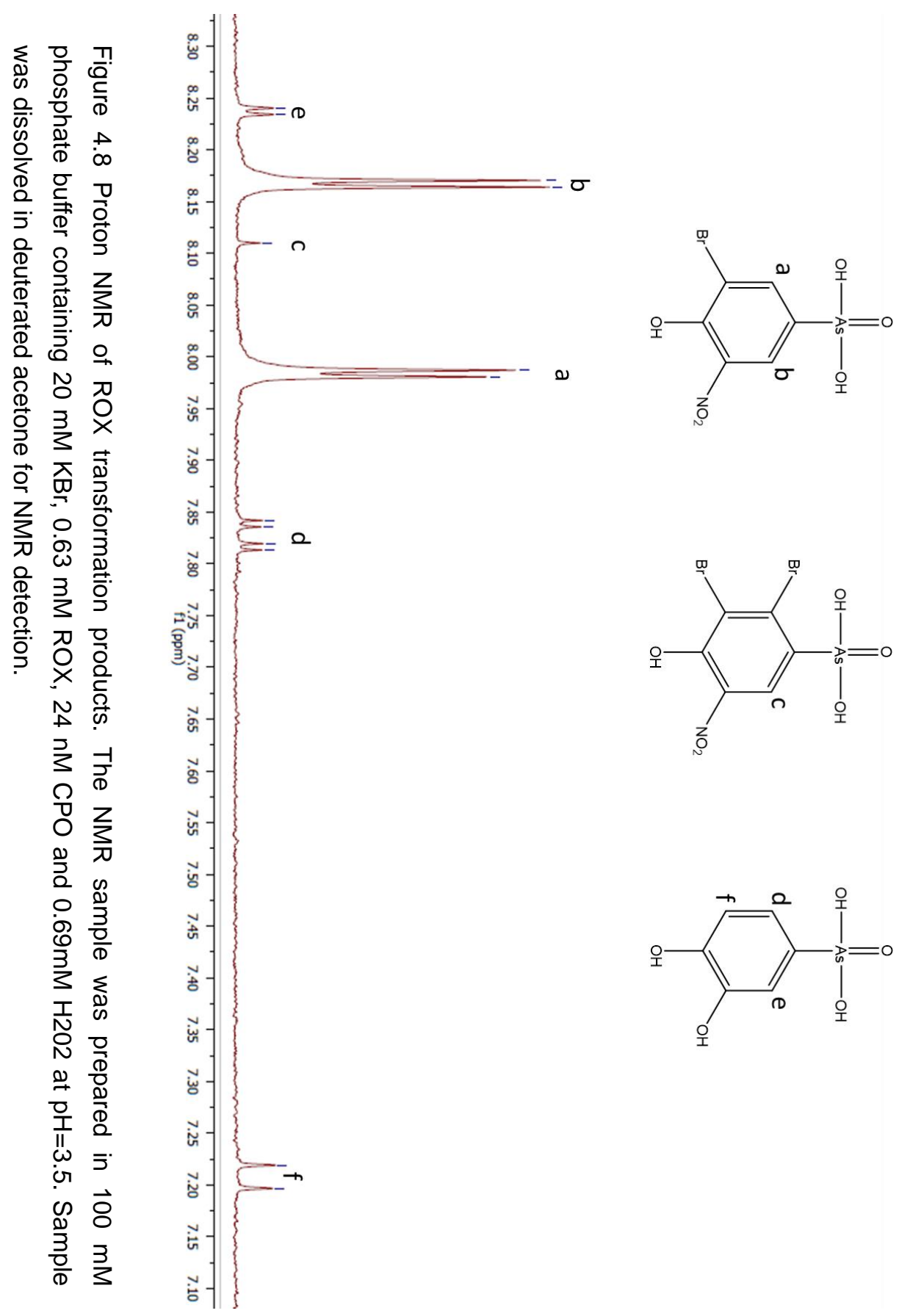


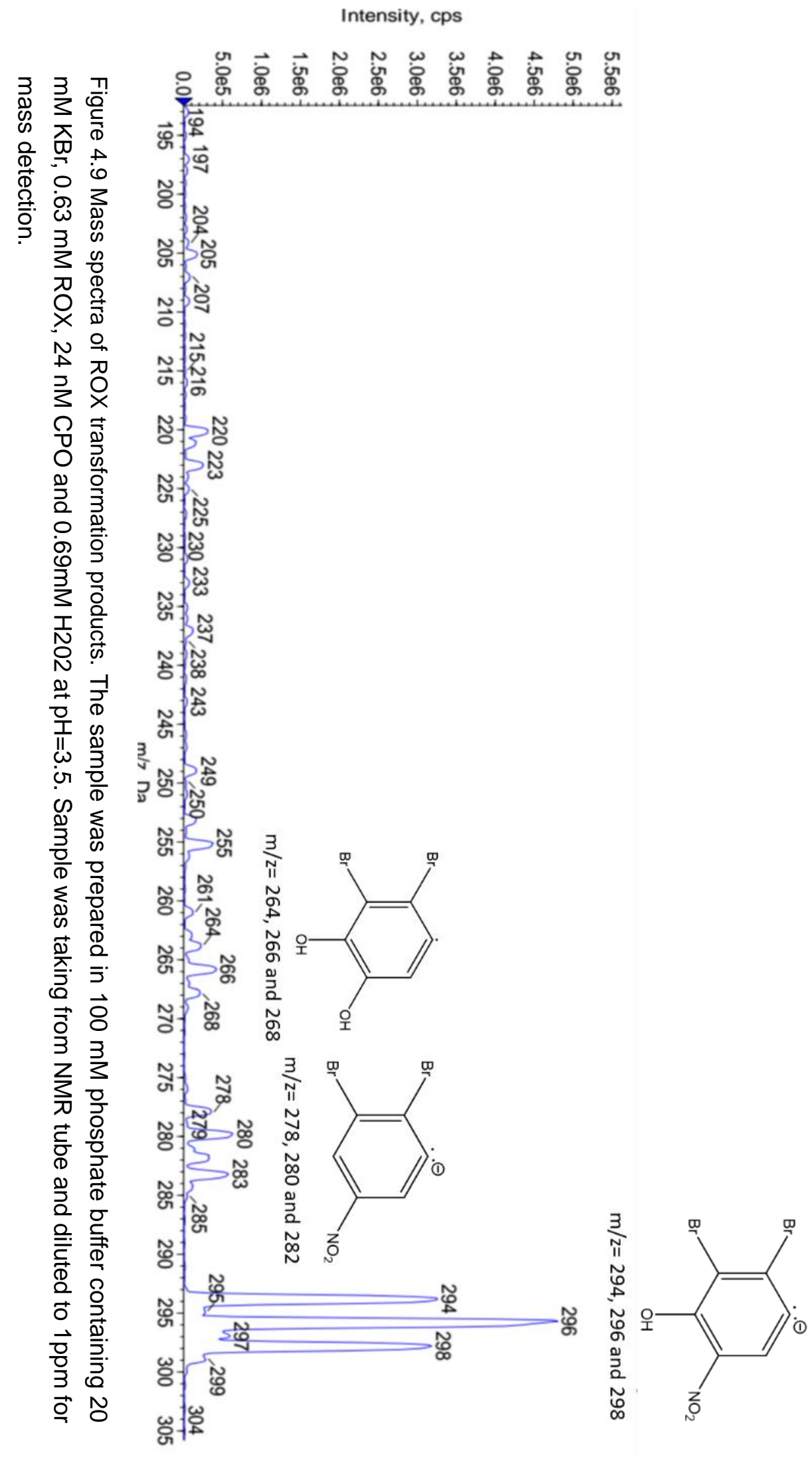


The transformation of ROX was confirmed by NMR and mass analysis of the reaction products. The NMR spectra suggested the formation of three products and two of them were shown on the mass spectra. The molecular ion detected on mass indicated the addition of two bromine atom to the parent compound, since a $1: 2: 1$ ratio of $M: M+2: M+4$ peaks is the isotopic signature of two bromine. The single bromination product was not observed in mass spectrum but gave two doublets at 7.98 and $8.16 \mathrm{ppm}$ in NMR with a coupling constant around 4, which indicates the addition of one bromine to the meta carbon of the hydroxyl group. The 264, 266 and $268 \mathrm{~m} / \mathrm{z}$ ratio, together with the single peak in NMR at $8.11 \mathrm{ppm}$ are consistent with the formation of a di-brominated product. Two positions exist as another bromine can be added at the benzene ring. However, the meta position carbon of the nitro group is less preferred because of the effect of steric hindrance and electronic directing effect of the nitro group. Therefore, the addition is proposed to be at the para position of the nitro group. The coupling pattern of this product indicates the hydroxylation of the nitro group, resulting in a doublet of doublets and two doublets in NMR, giving 264, 266 and $268 \mathrm{~m} / \mathrm{z}$ ratio in mass spectra with two bromine added. The molecular ions are not shown in the mass spectra for the easily decomposed characteristic of ROX and related metabolites. However, the fragmentation ions observed is in good agreement with the products proposed by NMR. 
4.3.6 Mechanism of CPO-catalyzed roxarsone transformation

Based on the products identified from NMR and mass spectroscopic studies, a mechanism of CPO-catalyzed transformation of ROX is proposed (Figure 4.10).

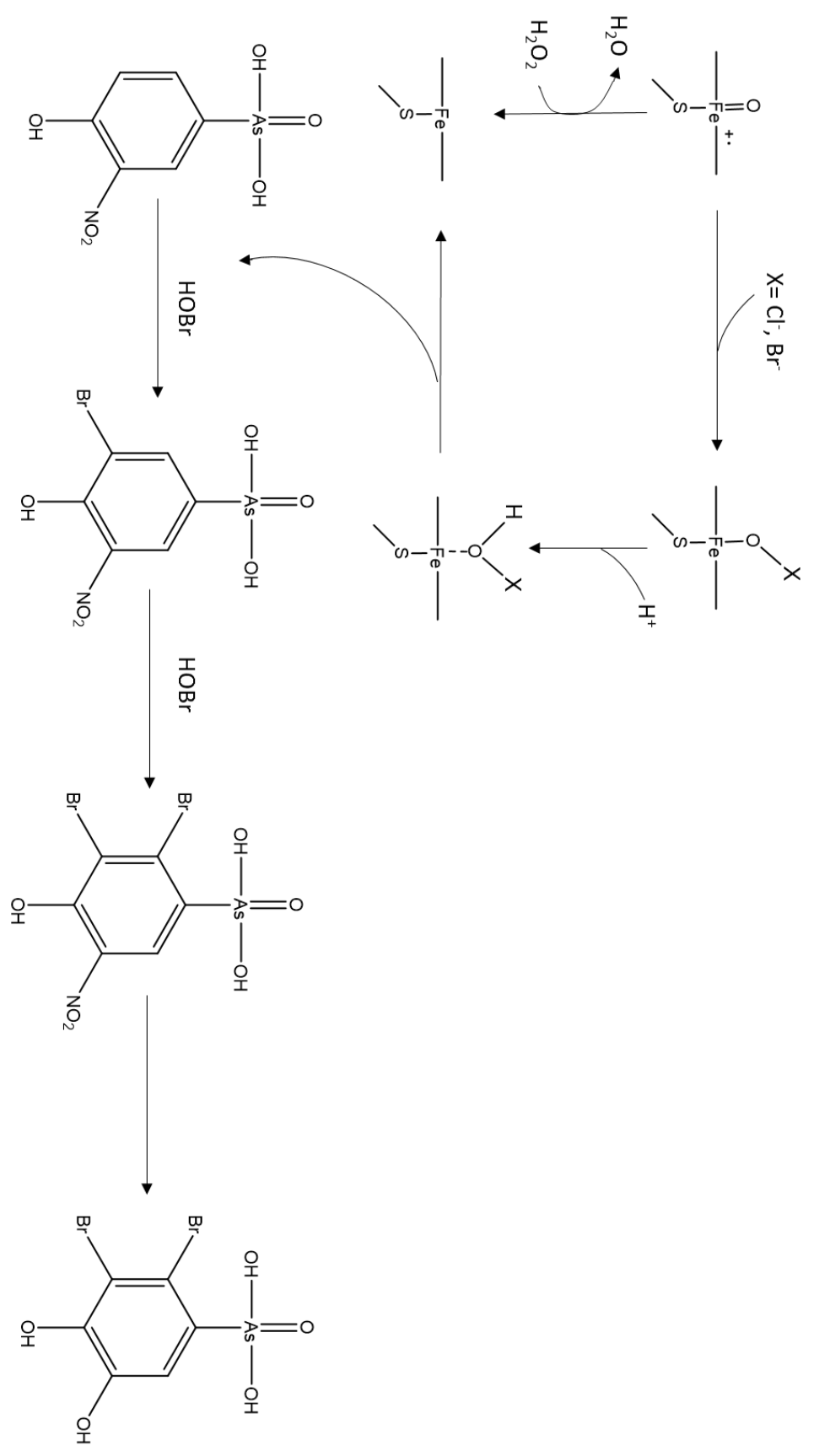

Figure 4.10 Proposed mechanism of ATV transformation $\left(\mathrm{C}=\mathrm{Cl}^{-}\right.$or $\left.\mathrm{Br}^{-}\right)$ 


\subsection{Conclusion}

In this work, we found that ROX is effectively transformed by CPO. The transformation can be achieved over a range of acidic $\mathrm{pH}(2.5$ to 5$)$ with the fastest transformation observed at $\mathrm{pH}=3.5$. The conversion required $\mathrm{H}_{2} \mathrm{O}_{2}$ with an optimal concentration range of $0.4-1 \mathrm{mM}$. The CPO catalyzed transformation of ROX followed Michaelis-Menten kinetics, with an $\mathrm{K}_{\mathrm{m}}$ of $23.61 \mu \mathrm{M}$ and $\mathrm{V}_{\max }$ of $3.98 \mu \mathrm{M} \mathrm{min}{ }^{-1}$. These parameters can be used as a measure for the preference of CPO to ROX and also to evaluate the effectiveness of the enzyme.

Both NMR and MS analyses demonstrated the bromination and hydroxylation of aromatic ring in ROX, showing the regioselectivity of $\mathrm{CPO}$ catalysis. During bromination, CPO converts ROX to either monobrominated (3-bromo-4-hydroxy-5 -nitrophenyl arsonic acid) or dibrominated (2,3-dibromo-4-hydroxy-5-nitrophenyl arsonic acid) products while the nitro group of ROX is hydroxylated. Based on the product identified, the mechanism of CPO-catalyzed transformation of ROX is proposed. The CPO-hypohalous acid complex is critical in the transformation in the proposed mechanism. The product analysis not only provides a better understanding of CPO catalyzed reactions, but also helps to evaluate the potential of this enzymatic method in environmental applications. While the process does not lead to mineralization, the observed product may be less toxic, more soluble, and more susceptible to further remediation processes. 
In general, the study provides a foundation for assessing the feasibility of applying CPO in the transformation of ROX contaminated water and soils for its high efficiency, cost-effectiveness and environmental friendly nature. This study also provides evidence about the general bromination mechanisms, which has promising potential in environmental applications. However, there are limitations such as the requirement for acidic conditions and the limited commercial availability of CPO. 


\section{REFERENCES}

1. Hughes, S.R., P. Kay, and L.E. Brown, Global Synthesis and Critical Evaluation of Pharmaceutical Data Sets Collected from River Systems. Environmental Science \& Technology, 2013. 47(2): p. 661-677.

2. Valcárcel, Y., et al., Detection of pharmaceutically active compounds in the rivers and tap water of the Madrid Region (Spain) and potential ecotoxicological risk. Chemosphere, 2011. 84(10): p. 1336-1348.

3. Kümmerer, K., Antibiotics in the Environment, in Pharmaceuticals in the Environment: Sources, Fate, Effects and Risks, K. Kümmerer, Editor. 2008, Springer Berlin Heidelberg: Berlin, Heidelberg. p. 75-93.

4. Kostich, M.S., A.L. Batt, and J.M. Lazorchak, Concentrations of prioritized pharmaceuticals in effluents from 50 large wastewater treatment plants in the US and implications for risk estimation. Environmental Pollution, 2014. 184: p. 354-359.

5. Ramirez, A.J., et al., Occurrence of pharmaceuticals and personal care products in fish: Results of a national pilot study in the united states. Environmental Toxicology and Chemistry, 2009. 28(12): p. 2587-2597.

6. Laville, N., et al., Effects of human pharmaceuticals on cytotoxicity, EROD activity and ROS production in fish hepatocytes. Toxicology, 2004. 196(1-2): p. 41-55.

7. Boxall, A.B.A., The environmental side effects of medication. EMBO reports, 2004. 5(12): p. 1110-1116.

8. Chen, L., et al., TiO2 photocatalytic degradation and detoxification of cylindrospermopsin. Journal of Photochemistry and Photobiology A: Chemistry. 307-308: p. 115-122.

9. Stackelberg, P.E., et al., Persistence of pharmaceutical compounds and other organic wastewater contaminants in a conventional drinking-water-treatment plant. Science of The Total Environment, 2004. 329(1-3): p. 99-113.

10. Organization, W.H., Pharmaceuticals in drinking-water. 2012. 
11. Ternes, T.A., et al., Removal of Pharmaceuticals during Drinking Water Treatment. Environmental Science \& Technology, 2002. 36(17): p. 3855-3863.

12. Nghiem, L.D., A.I. Schäfer, and M. Elimelech, Pharmaceutical Retention Mechanisms by Nanofiltration Membranes. Environmental Science \& Technology, 2005. 39(19): p. 7698-7705.

13. Hou, J., et al., Enzymatic degradation of bisphenol-A with immobilized laccase on TiO2 sol-gel coated PVDF membrane. Journal of Membrane Science, 2014. 469: p. 19-30.

14. Huber, M.M., et al., Oxidation of Pharmaceuticals during Ozonation and Advanced Oxidation Processes. Environmental Science \& Technology, 2003. 37(5): p. 1016-1024.

15. Tan, C., et al., Kinetic study of acetaminophen degradation by UV-based advanced oxidation processes. Chemical Engineering Journal, 2014. 253: p. 229-236.

16. Yuan, F., et al., Photodegradation and toxicity changes of antibiotics in UV and UV/H2O2 process. Journal of Hazardous Materials, 2011. 185(2-3): p. 1256-1263.

17. Zhang, R., et al., Degradation of Pharmaceuticals and Metabolite in Synthetic Human Urine by UV, UV/H2O2, and UV/PDS. Environmental Science \& Technology, 2015. 49(5): p. 3056-3066.

18. Cintas, P., Ultrasound and green chemistry--Further comments. Ultrasonics sonochemistry, 2016. 28: p. 257-258.

19. Doulah, M.S., A proposed mechanism for the degradation of addition polymers in cavitating ultrasonic fields. Journal of Applied Polymer Science, 1978. 22(6): p. 1735-1743.

20. Papadopoulos, C., et al., Sonochemical degradation of ethyl paraben in environmental samples: Statistically important parameters determining kinetics, by-products and pathways. Ultrasonics Sonochemistry, 2016. 31: p. 62-70. 
21. Musmarra, D., et al., Degradation of ibuprofen by hydrodynamic cavitation: Reaction pathways and effect of operational parameters. Ultrasonics Sonochemistry, 2016. 29: p. 76-83.

22. Kim, D.K., et al., Irradiation of ultrasound to 5-methylbenzotriazole in aqueous phase: Degradation kinetics and mechanisms. Ultrasonics sonochemistry, 2016. 31: p. 227-236.

23. Almeida, E.J.R. and C.R. Corso, Comparative study of toxicity of azo dye Procion Red MX-5B following biosorption and biodegradation treatments with the fungi Aspergillus niger and Aspergillus terreus. Chemosphere, 2014. 112: p. 317-322.

24. Jadhav, U.U., et al., Biodegradation of Direct Red 5B, a textile dye by newly isolated Comamonas sp. UVS. Journal of Hazardous Materials, 2008. 158(2-3): p. 507-516.

25. Mohan, S.V., et al., Acid azo dye degradation by free and immobilized horseradish peroxidase (HRP) catalyzed process. Chemosphere, 2005. 58(8): p. 1097-1105.

26. Keck, A., et al., Reduction of azo dyes by redox mediators originating in the naphthalenesulfonic acid degradation pathway of Sphingomonas sp. strain BN6. Applied and Environmental Microbiology, 1997. 63(9): p. 3684-3690.

27. Laurenti, E., et al., Oxidation of 2,4-dichlorophenol catalyzed by horseradish peroxidase: characterization of the reaction mechanism by UV-visible spectroscopy and mass spectrometry. Journal of Inorganic Biochemistry, 2003. 95(2-3): p. 171-176.

28. Nicell, J.A., et al., Enzyme catalyzed polymerization and precipitation of aromatic compounds from aqueous solution. Canadian Journal of Civil Engineering, 1993. 20(5): p. 725-735.

29. Husain, Q. and M. Husain, Peroxidases as a Potential Tool for the Decolorization and Removal of Synthetic Dyes from Polluted Water. 2012.

30. Hager, L.P., et al., Chloroperoxidase. II. Utilization of halogen anions. Journal of Biological Chemistry, 1966. 241(8): p. 1769-1777. 
31. Morris, D.R. and L.P. Hager, Chloroperoxidase: I. ISOLATION AND PROPERTIES OF THE CRYSTALLINE GLYCOPROTEIN. Journal of Biological Chemistry, 1966. 241(8): p. 1763-1768.

32. Casella, L., S. Poli, and A. Marchesini, The chloroperoxidase-catalyzed oxidation of phenols. Mechanism, selectivity, and characterization of enzyme-substrate complexes. Biochemistry.

33. van de Velde, F., et al., Chloroperoxidase-catalyzed enantioselective oxidations in hydrophobic organic media. Biotechnology and Bioengineering, 2001. 72(5): p. 523-529.

34. Sundaramoorthy, M., J. Terner, and T.L. Poulos, The crystal structure of chloroperoxidase: a heme peroxidase-cytochrome P450 functional hybrid. Structure, 1995. 3(12): p. 1367-1378.

35. Blanke, S.R. and L.P. Hager, Chemical modification of chloroperoxidase with diethylpyrocarbonate. Evidence for the presence of an essential histidine residue. Journal of Biological Chemistry, 1990. 265(21): $p$. 12454-61.

36. Dugad, L.B., et al., Proton nuclear Overhauser effect study of the heme active site structure of chloroperoxidase. Biochemistry, 1992. 31(6): $p$. 1651-1655.

37. Evans, S.V., SETOR: Hardware-lighted three-dimensional solid model representations of macromolecules. Journal of Molecular Graphics, 1993. 11(2): p. 134-138.

38. Kühnel, K., et al., Crystal Structures of Chloroperoxidase with Its Bound Substrates and Complexed with Formate, Acetate, and Nitrate. Journal of Biological Chemistry, 2006. 281(33): p. 23990-23998.

39. Hofrichter, M. and R. Ullrich, Heme-thiolate haloperoxidases: versatile biocatalysts with biotechnological and environmental significance. Applied Microbiology and Biotechnology, 2006. 71(3): p. 276.

40. Littlechild, J., Haloperoxidases and their role in biotransformation reactions. Current Opinion in Chemical Biology, 1999. 3(1): p. 28-34.

41. Murphy, C.D., New frontiers in biological halogenation. Journal of Applied Microbiology, 2003. 94(4): p. 539-548. 
42. KM, M. and H. LP, New insight into chloroperoxidase catalyzed reactions. Proceedings of the 14th International Conference on Cytochrome P450. 2005: p. 139.

43. Vázquez-Duhalt, R., M. Ayala, and F.J. Márquez-Rocha, Biocatalytic chlorination of aromatic hydrocarbons by chloroperoxidase of Caldariomyces fumago. Phytochemistry, 2001. 58(6): p. 929-933.

44. Yaipakdee, P. and L.W. Robertson, Enzymatic halogenation of flavanones and flavones. Phytochemistry, 2001. 57(3): p. 341-347.

45. Sanfilippo, C., N. D'Antona, and G. Nicolosi, Chloroperoxidase from Caldariomyces fumago is active in the presence of an ionic liquid as co-solvent. Biotechnology Letters, 2004. 26(23): p. 1815-1819.

46. Alvarez, R.G., et al., A novel biotransformation of benzofurans and related compounds catalysed by a chloroperoxidase. Tetrahedron, 2001. 57(40): p. 8581-8587.

47. Doerge, D.R. and M.D. Corbett, Peroxygenation mechanism for chloroperoxidase-catalyzed $\mathrm{N}$-oxidation of arylamines. Chemical Research in Toxicology, 1991. 4(5): p. 556-560.

48. Kedderis, G., D. Koop, and P. Hollenberg, N-Demethylation reactions catalyzed by chloroperoxidase. J Biol Chem, 1980. 255: p. 10174-10182.

49. Banerji, A., A.A. Long, and C.A. Camargo, Diphenhydramine versus nonsedating antihistamines for acute allergic reactions: A literature review. Allergy and Asthma Proceedings, 2007. 28(4): p. 418-426.

50. Hester, R.E. and R.M. Harrison, Pharmaceuticals in the Environment. 41(83).

51. Class, S., PHARMA REFORMULATES. Chemical \& Engineering News Archive, 2005. 83(49): p. 15-32.

52. Ternes, T.A., Occurrence of drugs in German sewage treatment plants and rivers1. Water Research, 1998. 32(11): p. 3245-3260.

53. Chiang, R., et al., Compound $X$. An intermediate in enzymatic halogenation. Journal of Biological Chemistry, 1976. 251(20): p. 6340-6346. 
54. Grey, C.E., M. Hedström, and P. Adlercreutz, A Mass Spectrometric Investigation of Native and Oxidatively Inactivated Chloroperoxidase. ChemBioChem, 2007. 8(9): p. 1055-1062.

55. Thomas, J.A., D.R. Morris, and L.P. Hager, Chloroperoxidase: VII. CLASSICAL PEROXIDATIC, CATALATIC, AND HALOGENATING FORMS OF THE ENZYME. Journal of Biological Chemistry, 1970. 245(12): p. 3129-3134.

56. Partani, P., et al., Simultaneous quantitation of atorvastatin and its two active metabolites in human plasma by liquid chromatography/(-) electrospray tandem mass spectrometry. Journal of Pharmaceutical Analysis, 2014. 4(1): p. 26-36.

57. Jomova, K., et al., Arsenic: toxicity, oxidative stress and human disease. Journal of Applied Toxicology, 2011. 31(2): p. 95-107.

58. Garbarino, J.R., et al., Environmental Fate of Roxarsone in Poultry Litter. I. Degradation of Roxarsone during Composting. Environmental Science \& Technology, 2003. 37(8): p. 1509-1514.

59. Hu, J., et al., Adsorption of roxarsone by iron (hydr)oxide-modified multiwalled carbon nanotubes from aqueous solution and its mechanisms. International Journal of Environmental Science and Technology, 2014. 11(3): p. 785-794.

60. Zheng, S., Y. Cai, and K.E. O'Shea, TiO(2) Photocatalytic Degradation of Phenylarsonic Acid. Journal of photochemistry and photobiology. A, Chemistry, 2010. 210(1): p. 61-68.

61. Zhu, X.-D., et al., Kinetics, intermediates and acute toxicity of arsanilic acid photolysis. Chemosphere, 2014. 107: p. 274-281.

62. Ayala, M., C.V. Batista, and R. Vazquez-Duhalt, Heme destruction, the main molecular event during the peroxide-mediated inactivation of chloroperoxidase from Caldariomyces fumago. JBIC Journal of Biological Inorganic Chemistry, 2011. 16(1): p. 63-68. 